\title{
APOL1 polymorphism modulates sphingolipid profile of human podocytes
}

\author{
Manuela Valsecchi ${ }^{1}$. Valentina Cazzetta ${ }^{1,2} \cdot$ Ferdinando Oriolo ${ }^{2} \cdot$ Xiqian Lan $^{3} \cdot$ Rocco Piazza $^{4} \cdot$ Moin A. Saleem ${ }^{5}$. \\ Pravin C. Singhal ${ }^{6} \cdot$ Domenico Mavilio $^{1,2} \cdot$ Joanna Mikulak $^{1,2} \cdot$ Massimo Aureli $^{1}(\mathbb{1})$
}

Received: 18 June 2020 / Revised: 19 August 2020 / Accepted: 2 September 2020 / Published online: 11 September 2020

(C) The Author(s) 2020

\begin{abstract}
Apolipoprotein L1 (APOL1) wild type (G0) plays a role in the metabolism of sphingolipids, glycosphingolipids, sphingomyelin and ceramide, which constitute bioactive components of the lipid rafts (DRM). We asked whether APOL1 variants (APOL1-Vs) G1 and G2 carry the potential to alter the metabolism of sphingolipids in human podocytes. The sphingolipid pattern in HPs overexpressing either APOL1G0 or APOL1-Vs was analysed by using a thin mono- and bi-dimensional layer chromatography, mass-spectrometry and metabolic labelling with $\left[1-{ }^{3} \mathrm{H}\right]$ sphingosine. HP G0 and G1/G2-Vs exhibit a comparable decrease in lactosylceramide and an increase in the globotriaosylceramide content. An analysis of the main glycohydrolases activity involved in glycosphingolipid catabolism showed an overall decrease in the activeness of the tested enzymes, irrespective of the type of APOL1-Vs expression. Similarly, the high throughput cell live-based assay showed a comparable increased action of the plasma membrane glycosphingolipid-glycohydrolases in living cells independent of the genetic APOL1 expression profile. Importantly, the most significative modification of the sphingolipid pattern induced by APOL1-Vs occurred in DRM resulted with a drastic reduction of radioactivity associated with sphingolipids. G1/G2-Vs present a decrease amount of globotriaosylceramide and globopentaosylceramide compared to G0. Additionally, ceramide at the DRM site and lactosylceramide in general, showed a greatest fall in G1/G2 in comparison with G0. Additionally, the levels of glucosylceramide decreased only in the DRM of human podocytes overexpressing G1/G2-Vs. These findings suggest that altered sphingolipidsprofiles may contribute to the deranged functionality of the plasma membrane in APOL1 risk milieu.
\end{abstract}

Keywords APOL1 $\cdot$ APOL1 polymorphism $\cdot$ HIVAN $\cdot$ Sphingolipids $\cdot$ Podocytes $\cdot$ Lipid rafts $\cdot$ Plasma membrane

Joanna Mikulak and Massimo Aureli contributed equally to this work.

Electronic supplementary material The online version of this article (https://doi.org/10.1007/s10719-020-09944-w) contains supplementary material, which is available to authorized users.

Massimo Aureli

massimo.aureli@unimi.it

1 Department of Medical Biotechnologies and Translational Medicine (BioMeTra), University of Milan, Milan, Italy

2 Unit of Clinical and Experimental Immunology, Humanitas Clinical and Research Center - IRCCS, Rozzano, MI, Italy

3 Key Laboratory for Aging and Regenerative Medicine, School of Pharmacy, Southwest Medical University, Luzhou, Sichuan, China

4 Department of Medicine and Surgery, University of Milan-Bicocca, Monza, Italy

5 Pediatric Academic Renal Unit, University of Bristol, Bristol, UK

6 Institute of Molecular Medicine, Feinstein Institute for Medical Research and Zucker School of Medicine at Hofstra-Northwell, Hempstead, NY, USA

\section{Introduction}

Apolipoprotein L1 (APOL1) is a minor component of plasma circulating High-Density Lipoprotein (HDL) capable to kill Trypanosoma brucei responsible for African sleeping sickness. [1-5]. The emerging resistance of the two specific variants (Vs) of APOL1 gene, termed G1 (rs73885319, p.S342G) and G2 (rs71785313, p.N388_Y389del), to the Trypanosoma brucei gambiense and rhodesiense infection increased their frequency in the residents of many regions of Africa as a consequence of pathogen positive selection [6]. Nevertheless, these two G1 and G2 APOL1 gene Vs, in contrast to the wild type (WT) G0 allele, have been shown to associate with several kidney pathologies including hypertension-attributed nephropathy, non-diabetic end-stage kidney disease, and the most strongly focal segmental glomerulosclerosis (FSGS) and HIV-associated nephropathy (HIVAN), an important complication of HIV infection characterized by collapsing FSGS associated to massive proteinuria 
[7, 8]. The pathogenesis of HIVAN is likely due to direct HIV infection of podocytes, the end-stage differentiated kidney epithelial cells critical for the glomerular filtration barrier $[9,10]$. Moreover, capturing of HIV by human podocytes (HPs) contribute to the establishment of the renal HIV reservoir important for viral spreading through trans-infection to lymphocytes [11].

APOL1 is a lipid-binding protein constitutively express in HPs and relevant for cellular homeostasis through endosomal trafficking and autophagy regulation, and activation of the inflammatory and innate immune response [12-15]. Many studies have already established that APOL1 risk Vs induce podocytes injury through mechanisms including increase of the lysosomal membrane permeability, mitochondrial dysfunction and impairment of endosomal and autophagic trafficking [16-20]. Additionally, we have previously shown that intracellular levels of HIV accumulation in HPs relies on expression of the APOL1 G1/G2-Vs upon inflammatory conditions [21]. However, there may be additional mechanisms by which APOL1-Vs injure HPs.

Taken together, these considerations let to speculate that plasma membrane could play an important role. In particular, among membrane lipids, sphingolipids (SLs) are directly involved in the regulation of the membrane homeostasis and signalling by the organization of specific macromolecular complex called lipid rafts. SLs are critical for proper function of the glomerular filtration barrier by regulating several podocytes functions such as: i) cell-to-cell interactions [22-26]; ii) cell survival and proliferation [26-28]; iii) endosomal trafficking [28, 29], and iv) pathogen capture including HIV [30, 31]. The family of the SLs include different classes of lipids with a varying degree of hydrophobic and hydrophilic proprieties. The hydrophobic region of SLs consists of a long chain sphingoid base, which is linked to a fatty acid via an amide bond. On the other hand, the hydrophilic portion could be composed by a hydroxyl group such as in the case of ceramide (Cer), phosphocholine in the case of sphingomyelin (SM) or by the combination of different saccharides forming the group of glycosphingolipids (GSLs). The diversity of GSLs is directed by a range of proteins involved in glycan biosynthesis including glycosyltransferases (GTs) and glycosidases, enzymes involved in glycan precursor biosynthesis and sugar transporters. These enzymes are diversely expressed in different types of human cells in order to achieve the cell specific SL plasma membrane functions. Indeed, alterations in the SLs pattern are usually associated with pathological conditions including podocyte injury [32].

Nevertheless, the genetic associations between APOL1-Vs and SL metabolism in HPs have not been investigated yet. Here we propose a study, schematically summarized in fig. 1, aimed to characterize the effect of the expression of APOL1 and its pathological variants on HPs in term of SL pattern and their catabolic enzymes.

\section{Results}

\section{Sphingolipid profile of human podocytes}

One of the main challenges in studying primary HPs is due to their terminally differentiated phenotype that has been overcame in part, by the in vitro development of conditionally immortalized HPs. This approach has greatly advanced our understanding of the physiopathology of HPs [33-35]; therefore, we took advantage of this established in vitro model to examine their SL profile. The analysis of SL pattern has been evaluated by combining mono- and bi-dimensional thin layer chromatography (HPTLC), mass-spectrometry (MS) and the metabolic tritium labelling at the steady state with $\left[1-{ }^{3} \mathrm{H}\right]$ sphingosine $\left(\left[1-{ }^{3} \mathrm{H}\right] \mathrm{Sph}\right)$. As expected, the SL pattern of HPs identified by HPTLC and MS analysis covers both neutral and polar SL species. Among analyzed complex SLs, the most abundant chain lengths of fatty acids present in HPs and their unsaturation degree were C16:0, C22:0, C24:1 and C24:0. The list and structure of all identified SLs in HPs is reported in supplementary Table 1 .

The endogenous and the metabolically tritium labeled SL pattern is reported in supplementary Fig. 1. Seven neutral SLs, covering over $85 \%$ of the total SLs, namely, ceramide, glucosylceramide, lactosylceramide, globotrihexosylceramide, ganglioteraosylceramide, sphingomyelin and globopentaosylceramide were identified by MS and comparison with authentic standards. Sphingomyelin is the major neutral SL in HPs, constituting over $26 \%$ of total SL content. Among the acidic SLs, the most representative is the ganglioside $\mathrm{GM}_{3}$, covering near $5 \%$ of total SLs. Moreover, we identified $\mathrm{GM}_{1 \mathrm{~b}}$ and $\mathrm{GD}_{1 \alpha}$, and the mono and disialylated forms of globopentaosylceramide $\left(\mathrm{Gb}_{5} \mathrm{Cer}\right)$. Quantification of the single SL types carried out on both endogenous and metabolically tritium labeled SLs resulted in comparable results. Indeed, as is shown in supplementary Fig. 1, a similar pattern and distribution of SLs were observed in both endogenous and metabolically tritium labeled SLs.

Common to other human cell types, also in HPs the main SL among non polar compounds are sphingomyelin $(26.3 \% \pm 2.8 \%$ of total cell SLs) and $\mathrm{GM}_{3}$ between ganglioside species (5.2\%土 $0.3 \%)$. In total SLs we also found globopentaosylceramide $(4.9 \% \pm 0.9 \%)$ and its two sialylated forms, monosialosylglobopentaosylceramide and disialosyl-globopentaosylceramide, that represent $4.5 \% \pm 0.3 \%$ and $0.4 \% \pm 0.2 \%$, respectively. These structures do not belong to the isogloboseries due to the lack of expression in HPs of A3GALT2 gene encoding for this enzyme. In fact, gene expression level of A3GALT2 was undetectable in whole-transcriptome analysis generated in human immortalized podocytes (HPs) and downloaded from the NCBI SRA database (accession number: SUB7456861; data not shown). On the other hand, a high expression level of A4GALT gene was revealed, thus indicating that detected 


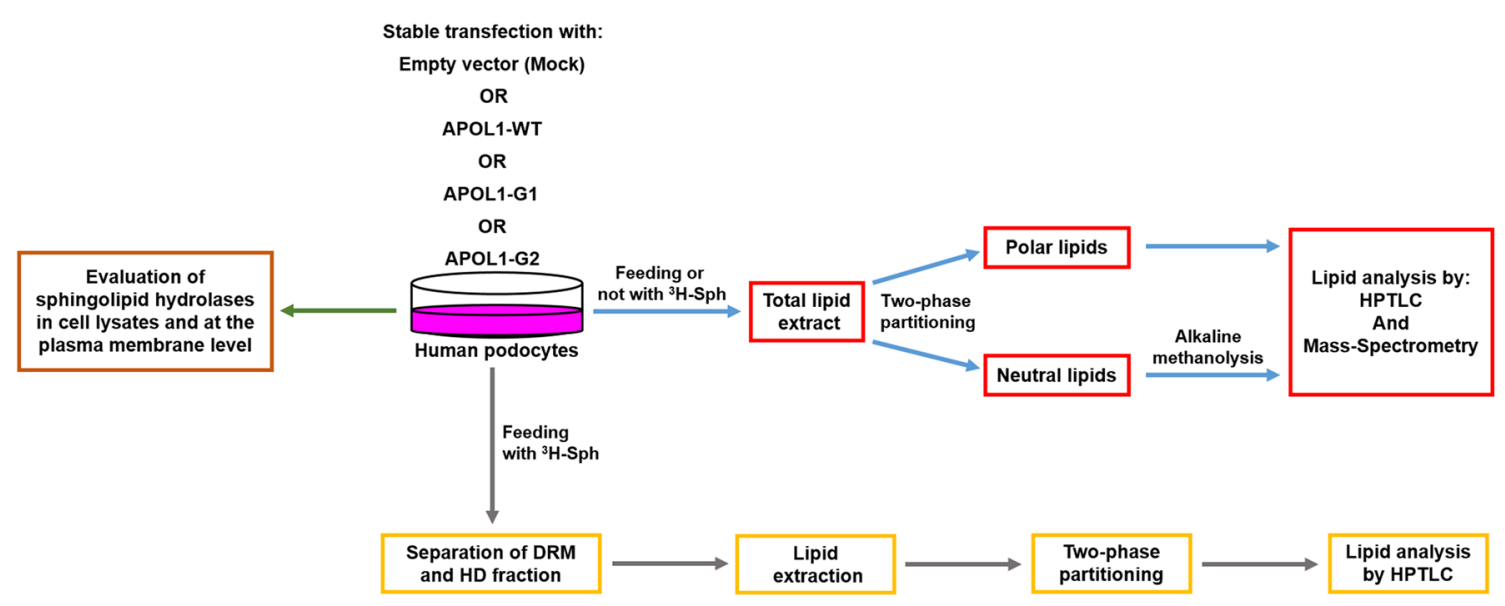

Fig. 1 Experimental pipeline followed to characterize podocytes expressing the different APOL1 Vs in term of SL composition and of the hydrolases involved in their catabolism

globopentaosylceramides in HPs belong to the globoseries (data not shown). The GA1 reaches $2.4 \% \pm 0.4 \%$ of all SLs, and the gangliosides $\mathrm{GM}_{1 \mathrm{~b}}$ and $\mathrm{GD}_{1 \alpha}$, constitute respectively $3.4 \% \pm$ $0.4 \%$ and $1 \% \pm 0.3 \%$ among all SLs. In addition, whole transcriptional data analysis in HPs evidenced gene expression of B4GALNT1 enzyme, thus confirming the presence of 0 -series gangliosides. The distribution of neutral SLs in HPs represents the following percentages listed in raising order: ceramide $5.7 \%$ $\pm 1 \%$; glucosylceramide $12.5 \% \pm 2.1 \%$; lactosylceramide $15.6 \% \pm 1.7 \%$, and globotriaosylceramide $18 \% \pm 2.6 \%$.

The mass spectra (MS1) with its corresponding fingerprints (MS2) shown in supplementary Fig. 2, confirmed the presence of 0 - and $\alpha$-series gangliosides in these cells and allowed to discriminate between the ganglio and globo series.

In supplementary Fig. 2, the sequence of ions at $m / z$ 1626.90, $1335.79,1173.75,970.67,808.62$ and 646.56, suggests a Neu5Ac-Hex-HexNHAc-Hex-Hex-Cer structure characteristic of $\mathrm{GM}_{1}$, with the lack of the fragment ion at $m / z 1261.78$ that is characteristic for the $\mathrm{GM}_{3}$ structure Neu5Ac-Hex-Hex-Cer. Moreover, when this ganglioside was treated with $V$. Cholera sialidase, $\mathrm{GM}_{1}$ converted to gangliotetraosylceramide (data not shown). The $V$. Cholera sialidase in vitro does not act on the inner sialic acid, confirming the position of the residue of sialic acid, bound to the terminal Gal. Taken all together, these results indicate that the sialidase-labile $\mathrm{GM}_{1}$ is $\mathrm{GM}_{1 \mathrm{~b}}$, as also suggested by others $[25,36]$. Similarly, $\mathrm{GD}_{1}$ represented by the MS2 spectrum derived from the ion at $m / z$ 945.51, coincident with its doubly charged ion, contains the ions corresponding to Neu5Ac at $m / z$ 290.11, (Neu5Ac-)HexNHAc at $m / z$ 493.19, (Neu5Ac-)Hex-HexNHAc-Hex at $m / z \quad 835.29$ and (Neu5Ac-)Hex-(Neu5Ac-)HexNHAc at $m / z$ 964.35 respectively. As already reported [36], we didn't detect the fragment ion corresponding to $\mathrm{GM}_{3}$ at $m / z$ 1235.81, present in the case of $\mathrm{GD}_{1 \mathrm{a}}$, and no fragment ion corresponding to (Neu5Ac-) $)_{2}$ at $m / z 581.22$ was found, a typical fragment ion of $\mathrm{GD}_{1 \mathrm{~b}}$. Moreover, upon the treatment with $V$. Cholera sialidase it was converted to $\mathrm{GM}_{1}$ and gangliotetraosylceramide (data not shown), confirming that sialic acids were bound to the terminal Gal and to the adjacent GalNAc, respectively. All these data indicate that the sialidaselabile $\mathrm{GD}_{1}$ is $\mathrm{GD}_{1 \alpha}$.

Regarding the globo-series of SLs $\left(\mathrm{Gb}_{5} \mathrm{Cer}\right.$, Neu5AcGb $\mathrm{Aber}_{5}$ and (Neu5Ac) ${ }_{2} \mathrm{~Gb}_{5} \mathrm{Cer}$ ), their identification was based on the typical sequential fragmentation of their oligosaccharide chain. For $\mathrm{Gb}_{5} \mathrm{Cer}$, the MS2 spectrum derived from the ion at $\mathrm{m} / \mathrm{z}$ 1387.92 showed a series of ions at $\mathrm{m} / \mathrm{z}$ 1225.87, 1022.79, $860.74,698.68$ and 536.63, corresponding to the sequential detachment of sugar moieties. Furthermore, the MS2 spectrum derived from the ion at $m / z 895.00$, corresponding to the doubly charged ion of $\mathrm{Neu} 5 \mathrm{AcGb}_{5} \mathrm{Cer}$, contained the ions corresponding to Neu5Ac at $m / z$ 290.11, (Neu5Ac-)Hex at $m / z 470.16$ and (Neu5Ac-)Hex-HexNHAc-Hex at $m / z$ 835.29, respectively, as previously described [37]. For (Neu5Ac) ${ }_{2} \mathrm{~Gb}_{5} \mathrm{Cer}$, in the MS2 spectrum derived from the ion at $m / z$ 1039.56, corresponding to the doubly charged ion of (Neu5Ac) $)_{2} \mathrm{~Gb}_{5} \mathrm{Cer}$, the presence of the ions corresponding to Neu5Ac at $\mathrm{m} / \mathrm{z}$ 290.11, (Neu5Ac-)HexNHAc at $m / z, 493.19$ and (Neu5Ac-)HexNHAcHex-Hex at $m / z$ 835.29, respectively, is consistent with its structure already reported in literature [38, 39]. When sialylated forms of $\mathrm{Gb}_{5} \mathrm{Cer}$ were treated with $V$. Cholera sialidase, they converted to GA1 (data not shown), confirming that sialic acids are linked to the terminal Gal in $\mathrm{MSGb}_{5}$ Cer and in $\mathrm{DSGb}_{5} \mathrm{Cer}$, and to the adjacent GalNAc in (Neu5Ac) ${ }_{2} \mathrm{~Gb}_{5} \mathrm{Cer}$. To further confirm the structure of (Neu5Ac $)_{2} \mathrm{~Gb}_{5} \mathrm{Cer}$ we did not find the fragment ion (Neu5Ac- $)_{2}$ at $m / z$ 581.22. Of note, we did not detect $\mathrm{GD}_{3}$ or Oacetylated- $\mathrm{GD}_{3}$ previously described within the rat podocytes, probably because of the specie-specific differences in the expression of some gangliosides between rodents and humans [40, 41].

\section{The overexpression in human podocytes of WT and G1 and G2 APOL1-Vs has differential effects on sphingolipids pattern and metabolism}

APOL1 is an integral component of HDL particles that might be involved in cholesterol efflux from the cell, membrane 
homeostasis, oxidative stress, phospholipid transport and regulation of intracellular processes, including autophagy and vesicle transport. However, studies to shed light on the role of WT and the specific APOL1-Vs on SLs homeostasis in HPs under both physiological and pathological conditions are needed. Therefore, we use the HPs in vitro model overexpressing WT APOL1 or either the two G1/G2 APOL1-Vs to study the metabolism of SLs. We have validated an equivalent $A P O L 1$ gene expression level in all HP samples by real time PCR analysis (data not shown) and by whole-transcriptome data generated in these cells (NCBI SRA database; accession number: SUB7456861) and reported in supplementary Fig. 3. By the analyses of the SL profile, we observed that the stable overexpression of the WT form of APOL1 in HPs induce a decrease in the total cell content of the lactosylceramide of about $42 \% \pm 6 \%$ and an increase of the $30 \% \pm 3 \%$ of the globotriaosylceramide (Fig. 2). Interestingly, the overexpression of the risk proteins of APOL1 G1 and G2 induce similar changes in almost all the podocyte SLs with the exception for the gangliosides $\mathrm{GM}_{3}, \mathrm{GM}_{1 \mathrm{~b}}$ and globotriaosylceramide. Indeed, the overexpression of G1 and G2 Vs induces an increase of: $50 \% \pm 3 \%$ for the monosialosyl-globopentaosylceramide, $53 \% \pm 2 \%$ for the disialosyl-globopentaosylceramide, $58 \% \pm 9 \%$ for the ganglioside $\mathrm{GD}_{1 \alpha}$, and $52 \% \pm 3 \%$ for the sphingomyelin. On the contrary, the overexpression of the two APOL1-Vs induces a decrease of: $34 \% \pm 4 \%$ for the globopentaosylceramide, $36 \% \pm$ $2 \%$ for the GA1, $86 \% \pm 19 \%$ for the ceramide, $29 \% \pm 2 \%$ for the glucosylceramide, and $42 \% \pm 6 \%$ for the lactosylceramide.

We than analysed the activity of the main glycohydrolases involved in the glycosphingolipid catabolism. As is shown in Fig. 3, a significant decrease in the activity of the tested enzymes, independently on the overexpression of WT or APOL1-Vs, were found.

The same glycohydrolases enzymes are also located at the cell surface, where they are directly involved in the in situ modification of the SL composition at the plasma membrane. By a high throughput cell live-based assay, we measured the enzymatic activity of the sphingolipid-glycohydrolases at the plasma membrane site directly on living cells. Interestingly, as shown in Fig. 4 we found an increased activity for all the enzymes tested. Notable, the non-lysosomal beta-glucosylceramidase (NLGase) increased, only in case of the specific G2 risk variant overexpression. These data strongly suggest that the changes observed in the lipid composition after overexpression of the WT and APOL1Vs could also be due to the action of the glycosphingolipidhydrolases located at the cell membrane surface.

\section{The overexpression of APOL1 WT, G1 and G2 Vs alters the lipid rafts composition of human podocytes}

The podocyte slit diaphragm, which has a critical role in the formation and maintenance of the glomerular filtration barrier, is assembled in the so called lipids rafts or detergent resistant membrane fractions (DRM). These small (10-200 nm diameter) specialized plasma membrane domains are enriched with SLs, cholesterol and protein complexes that have different roles in signal transduction and cell homeostasis. In the context of HIV infection, our previous work has shown that cholesterol (maintenance of DRM integrity) is required for HIV internalization in HPs [30]. In addition, as described before, we found that the overexpression of the APOL1-Vs strongly impacts the SL pattern of the HPs. Based on these considerations, mock HPs and overexpressing WT or G1/G2Vs of APOL1 were fed with radioactive sphingosine in order to obtain the metabolic labelling at the steady state of all cell SLs. Subsequently DRM were isolated from plasma membrane and other cellular fractions on a discontinuous sucrose gradient as described in the methods. Eleven fractions were collected and analysed by Western blot for the positive (caveolin-1) and negative (calnexin) DRM markers. As shown in Fig. 5A, we found that fraction 5 and 6 are enriched in the DRM marker Caveolin-1 (Cav-1) compared to the highdensity fractions 10 and 11 . On the contrary, calnexin, a protein not associated with DRM, was undetectable in fractions 5 and 6 while it was detected in fractions 10 and 11 . We than evaluated the radioactivity associated with each faction as an indicator of the SL distribution (Fig. 5B). We observed that mock and podocytes overexpressing WT APOL1 are characterized by similar radioactivity associated with SLs in the DRM fractions 5 and 6, whereas in DRM, isolated from HPs overexpressing the risk APOL1-Vs, the SL associatedradioactivity was reduced, thus suggesting that the overexpression of the pathological APOL1-Vs might negatively influence the SL composition of DRM in HPs.

Further analysis of the SL pattern associated specifically with the DRM was performed on the fractions 5 and 6 pulled together and compared with the pulled fractions 10 and 11 of the detergent soluble membrane. The DRM obtained from mock HPs are enriched in the amount of almost all SLs, with exception of the $\mathrm{GM}_{1 \mathrm{~b}}$ which is present at the same level observed in the detergent soluble fractions (Fig. 6).

As shown in Fig. 7, the comparison among the SL pattern of ganglio-series in the DRM obtained from mock HPs or either expressing G0 or risk APOL1-Vs reveals that: i) the overexpression of the WT protein induces a reduction in the content of the $\mathrm{GM}_{3}$ and $\mathrm{GD}_{1 \alpha}$; ii) $\mathrm{G} 1$ causes more evident reduction of $\mathrm{GM}_{3}$ (around $35 \%$ ), $\mathrm{GM}_{1 \mathrm{~b}}$ is reduced by $50 \%$, and $\mathrm{GD}_{1 \alpha}$ by about $40 \%$; iii) $\mathrm{G} 2$ induces variations of $\mathrm{GM}_{3}$, which decreases by about $50 \%$. The GA1 decreases by about $60 \%$ in podocytes overexpressing APOL1-G0 and more than $70 \%$ for G1 and G2 APOL1-Vs.

Significant changes due to the overexpression of all APOL1 proteins were observed in DRM also for the content of sphingolipids from globo-series (Fig. 8) and other sphingolipids (Fig. 9). $\mathrm{Gb}_{3}$ Cer increases in WT APOL1 and decreases $25 \%$ in G1 and $18 \%$ in G2 APOL1. $\mathrm{Gb}_{5}$ Cer decreases in WT APOL1 and G2 (44\% and 60\%, respectively), reaching the highest 
$\mathrm{GM}_{3}$

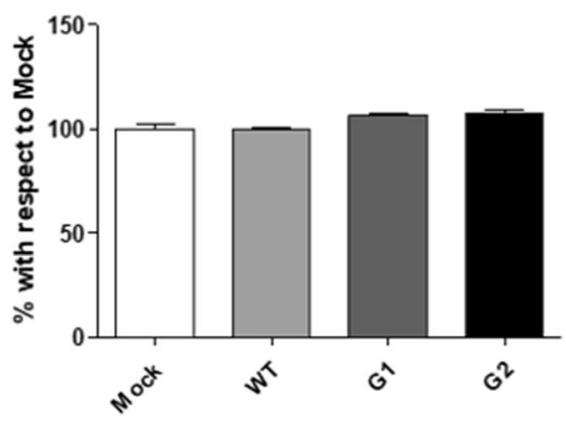

DSGb $_{5}$ Cer

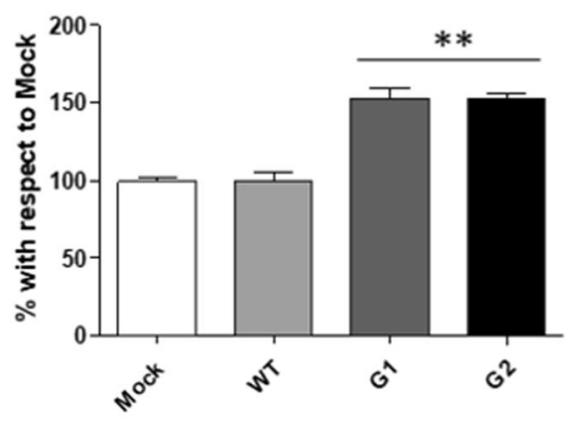

GA1

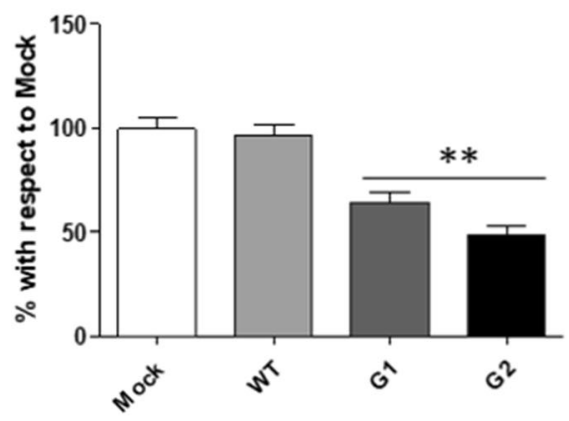

LacCer

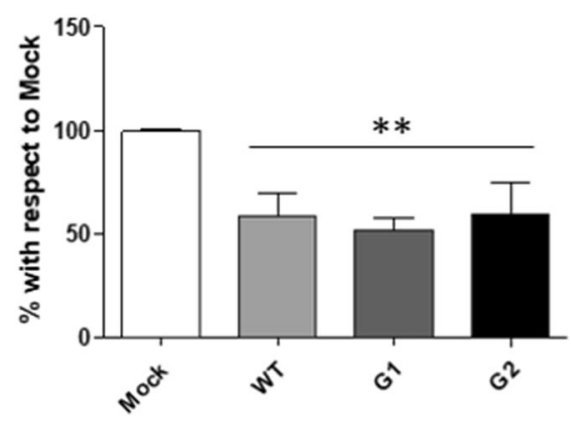

Fig. 2 Effects of the overexpression of APOL1 WT, G1 and G2 Vs on the sphingolipid pattern of human podocytes. Cell sphingolipids were metabolically labelled at the steady state with $\left[1-{ }^{3} \mathrm{H}\right]$ sphingosine, separated by HPTLC, visualized by digital autoradiography and quantified with M3 software. Data are expressed as percentage with respect to Mock cells. Gangliotetraosylceramide (GA1),
$\mathrm{MSGb}_{5} \mathrm{Cer}$

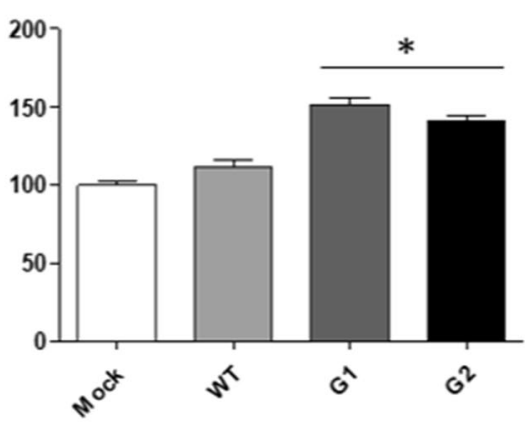

$G_{1 \alpha}$

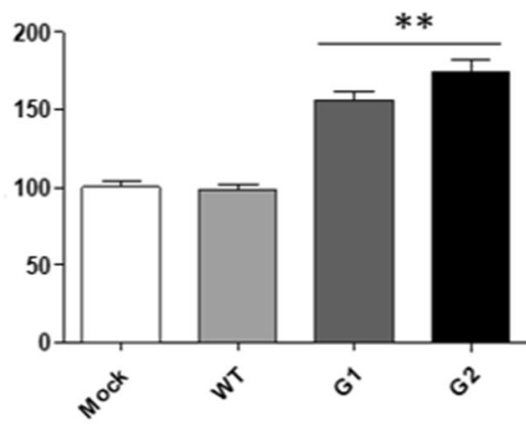

Cer

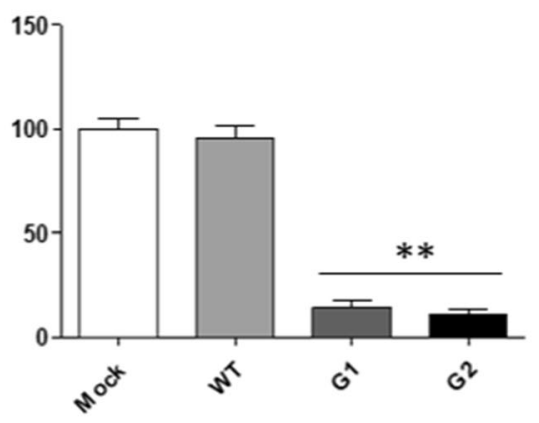

$\mathrm{Gb}_{3} \mathrm{Cer}$

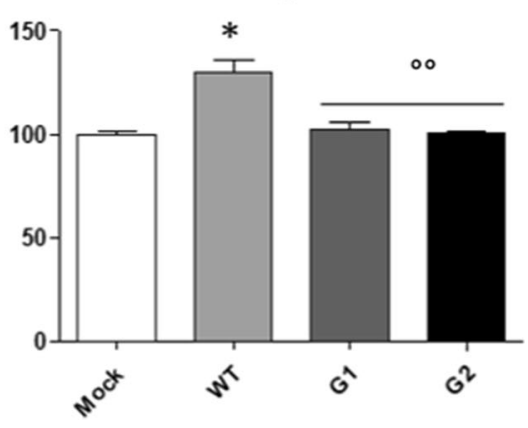

globotriaosylceramide $\left(\mathrm{Gb}_{3} \mathrm{Cer}\right)$, globopentaosylceramide $\left(\mathrm{Gb}_{5} \mathrm{Cer}\right)$, monosialosyl-globopentaosylceramide $\left(\mathrm{MSGb}_{5} \mathrm{Cer}\right)$, disialosylglobopentaosylceramide ( $\mathrm{DSGb}_{5} \mathrm{Cer}$ ), ceramide (Cer), glucosylceramide (GlcCer), lactosylceramide (LacCer), sphingomyelin (SM). * $p<0.05$ vs Mock, ${ }^{* *} p<0.005$ vs Mock, ${ }^{\circ} \mathrm{p}<0.005$ vs WT
$\mathrm{GM}_{1 \mathrm{~b}}$

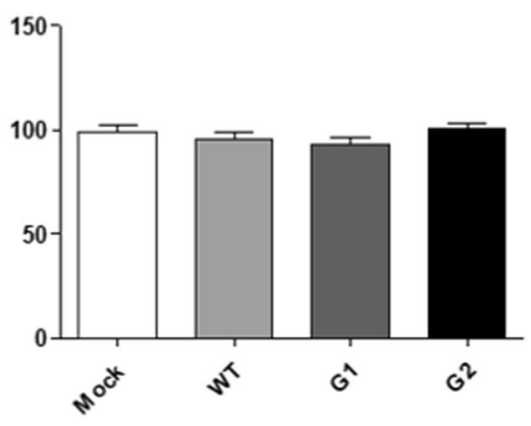

$\mathrm{Gb}_{5} \mathrm{Cer}$

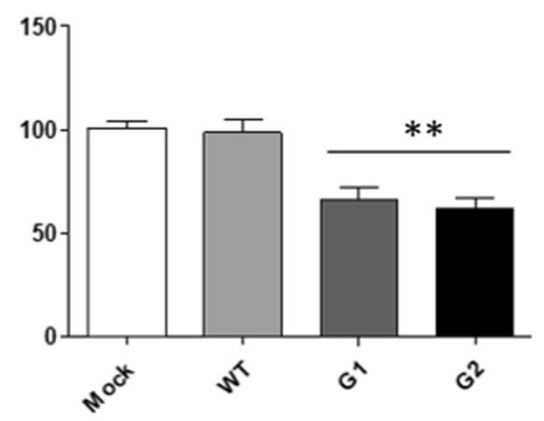

GlcCer

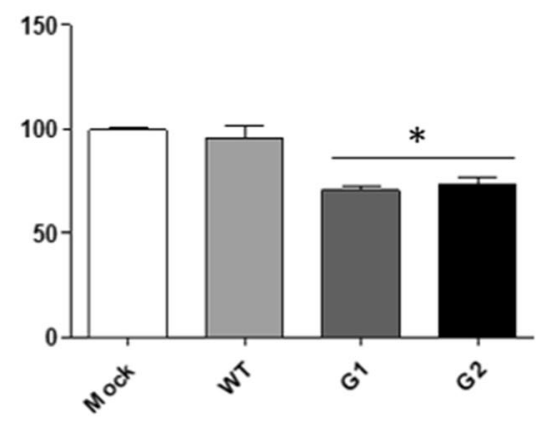

SM

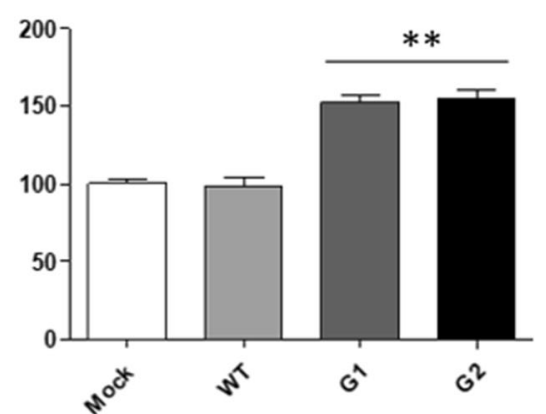


Fig. 3 Effects of the overexpression of APOL1 WT, G1 and G2 Vs on the activity of total cell sphingolipidhydrolases. Hydrolases activity were evaluated on cell lysate by an in vitro enzymatic assay using artificial fluorogenic substrates. $\beta$-glucocerebrosidase (Gcase), non-lysosomal

glucosylceramidase (NLGase).

The enzymatic activities are expressed as pmoles $/ \mathrm{mg}$ of cell proteins per hour. $* * p<0.005$ vs Mock
GCase

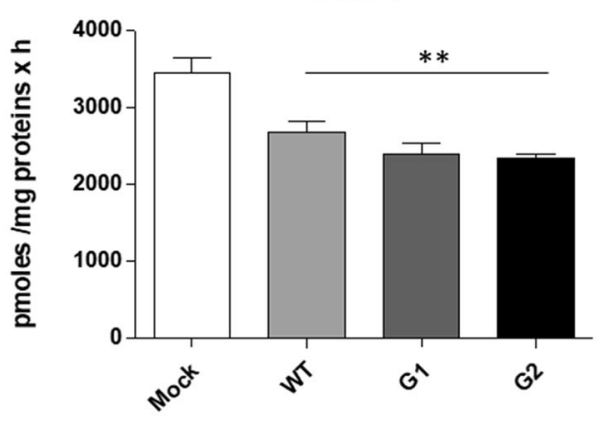

$\alpha$-galactosidase

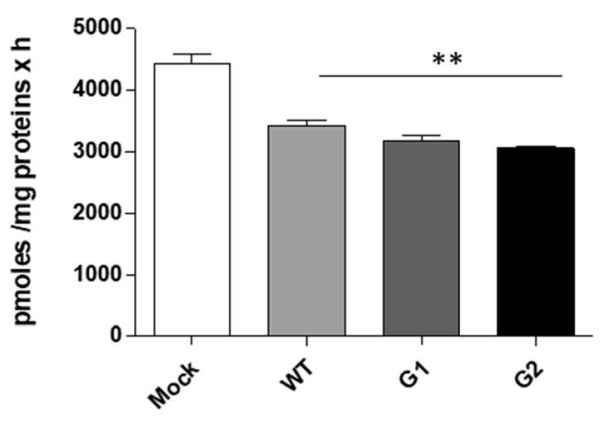

$\beta$-hexosaminidase

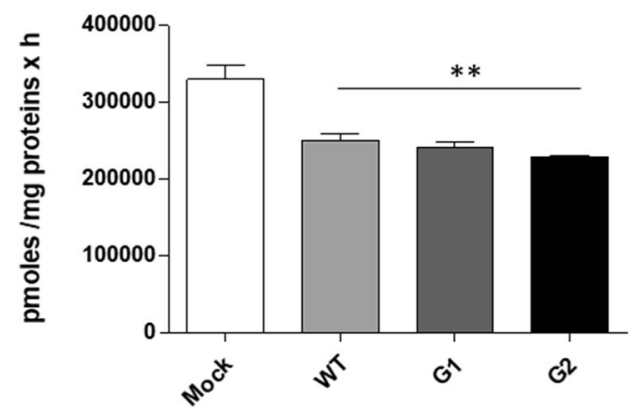

NLGase

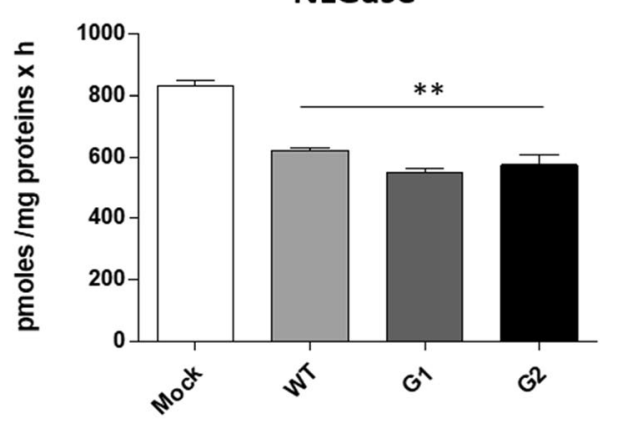

$\beta$-galactosidase

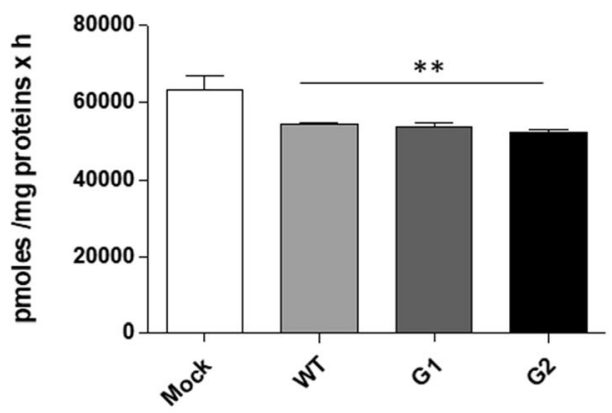

reduction in G1 APOL1 (89\%). MSGb ${ }_{5}$ Cer decreases about $20 \%$ only in the pathological APOL1-Vs. DSGb ${ }_{5}$ Cer slightly increases in podocytes overexpressing the WT APOL1, decreases in G1 and strongly increases in G2 (81\%).

As regards other SLs, the lipid rafts ceramide content decreases by about $25 \%$ on WT APOL1, a more consistent decrease was observed in G1 and G2 where it reached 80 and $88 \%$, respectively. The levels of glucosylceramide decrease only in the DRM prepared from podocytes overexpressing the APOL1 pathological Vs. The lactosylceramide is reduced $50 \%$ in WT and $65 \%$ in G1 and G2. No changes among the mock and APOL1-Vs were observed for the SM content in the DRM.

\section{Discussion}

APOL1 genetic Vs are potent risk factors for HIVAN [7, 8]. Importantly, a single copy APOL1 risk allele (i.e., when present in a heterozygous state with the G0 allele) is sufficient to increase the risk for HIVAN [42]. The specific role of APOL1 protein in the development of HIVAN is still under investigation, however, poorly controlled HIV infection is the most potent susceptibility factor for APOL1-associated nephropathy that has been identified to date [19]. Moreover, studies of APOL1 localization in human kidney biopsies with HIVAN compared to normal kidney sections observed increased expression of APOL1 protein [43]. In fact, several reports demonstrated the direct impact of APOL1 protein on HIV infection [15, 18-21]. In particular, HIV infection in HPs is able to increase expression of APOL1 creating a positivefeedback loop enhancing infection and inflammatory response particularly relevant for APOL1 risk Vs [21]. On the other hand, several lines of evidence derived from clinical and experimental studies have provided insights into the roles of lipids and lipid-modulating proteins as key determinants of podocyte function in health and kidney disease [23]. 
Fig. 4 Effects of the overexpression of APOL1 WT, G1 and G2 Vs on the activity of the sphingolipid-hydrolases associated with plasma

membrane. Hydrolases activity were evaluated at the plasma membrane on living cells using artificial fluorogenic substrates. $\beta$-glucocerebrosidase (Gcase), non-lysosomal glucosylceramidase (NLGase). The enzymatic activities are expressed as pmoles $/ 10^{6}$ cell per hour. $* p<0.05$, vs Mock **p $<$ 0.005 vs Mock, $* * * p<0.0005$ vs Mock, ${ }^{\circ} \mathrm{p}<0.05$ vs WT, ${ }^{\circ} \mathrm{p}<$ 0.005 vs WT, \# $\mathrm{p}<0.005$ vs G1, $\#$ \# $<0.005$ vs G1
GCase

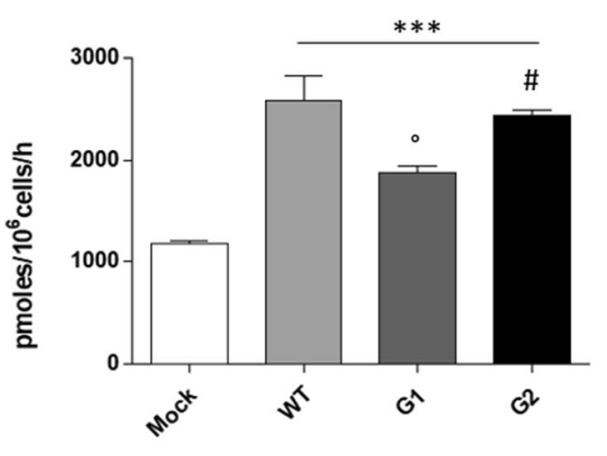

$\alpha$-galactosidase

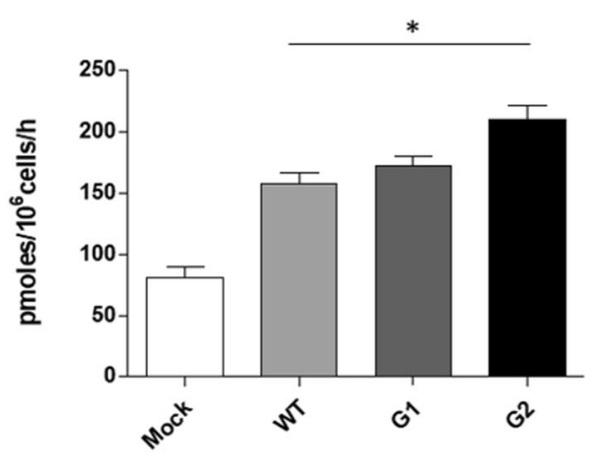

$\boldsymbol{\beta}$-hexosaminidase

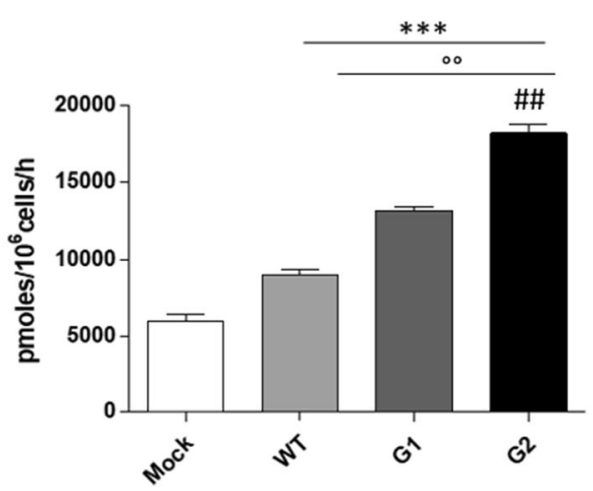

NLGase

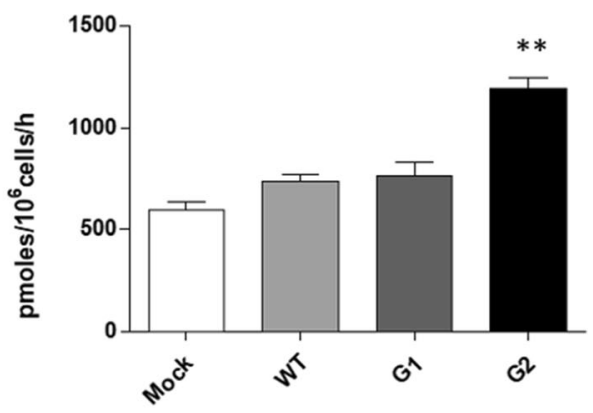

$\beta$-galactosidase

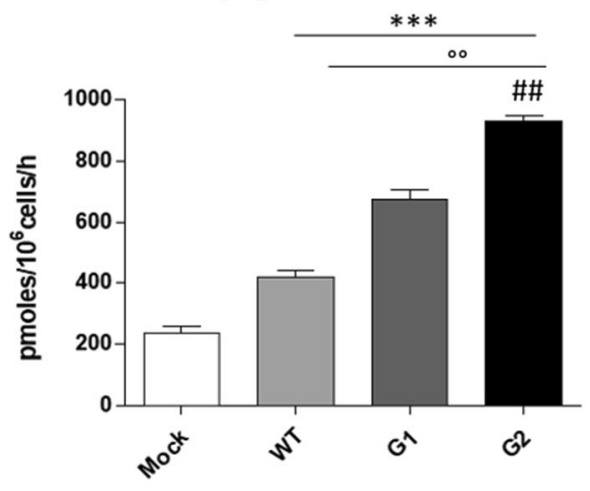

Thus, to study the impact of APOL1 on SLs pattern in the context of HIVAN we used the established HPs model with the increased expression level of APOL1 G0/WT or either G1 or G2 risk Vs.

Of note, podocytes are characterized by a peculiar lipid pattern especially for the SLs composition. Indeed, besides to classical SLs present in somatic cells such as $\mathrm{GM}_{3}$ and SM, HPs express several unusual SLs including $\mathrm{GM}_{1 \mathrm{~b}}, \mathrm{GD}_{1 \alpha}$, and globopentaosylceramide $\left(\mathrm{Gb}_{5} \mathrm{Cer}\right)$ with its sialylated monosialosyl-globopentaosylceramide $\left(\mathrm{MSGb}_{5} \mathrm{Cer}\right)$ and disialosyl-globopentaosylceramide ( $\mathrm{DSGb}_{5} \mathrm{Cer}$ ). SLs due to their physical and chemical properties segregates at the plasma membrane level forming the so-called DRM. Despite SLs, DRM are enriched in cholesterol and in a specialized class of proteins able to form different macromolecular complexes that not only have a structural role, but also are an active player in the control of cell signalling [44]. The importance of DRM in the glomerular slit-diaphragm was recognized several years ago when proteins express in podocytes such as nephrin and podocin were found to be enriched in DRM [23]. Moreover, in podocytes lipid rafts-associated ganglioside $\mathrm{GM}_{3}$ is a receptor for the soluble Flt1 protein which binding is essential for autocrine preservation of the podocyte actin cytoskeleton and prevention of proteinuria [26]. On the other hand, alteration in 

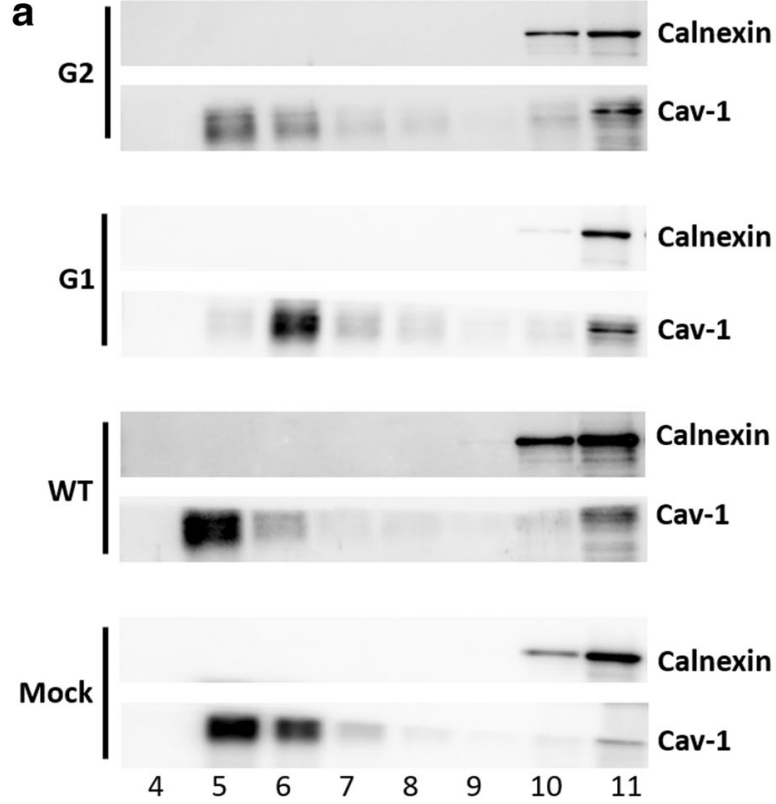

b

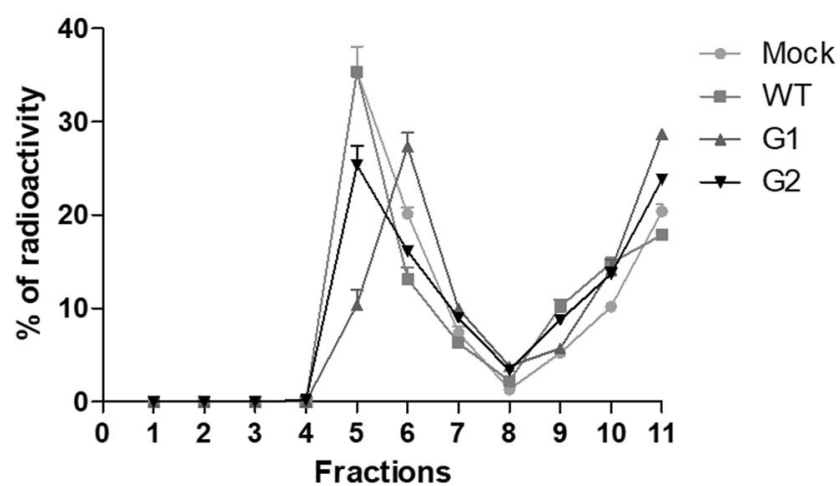

Fig. 5 DRM separation from podocytes overexpressing APOL1 WT, G1 and G2 Vs. Cell sphingolipids were metabolically labelled at the steady state with $\left[1-{ }^{3} \mathrm{H}\right]$ sphingosine and DRM were separated on discontinuous sucrose gradient loading the same amount of cell lysates and corresponding to $2 \mathrm{mg}$ of cell proteins and $225 \mathrm{nCi}$ of radioactivity. A) Representative western blot of calnexin (not DRM marker) and caveolin-1 (Cav-1, DRM marker) in the gradient fractions obtained by the different cell line analyzed. B) Distribution of radioactivity among gradient fractions

the SLs composition, which in turn induces impairment of the lipid's rafts structure, was reported in several kidney-related pathologies. In the podocytes of patients with Fabry disease, the accumulation of globotriaosylceramide $\left(\mathrm{Gb}_{3} \mathrm{Cer}\right)$ is associated with proteinuria and podocyte injury [45]. In Sandhoff disease, the accumulation of the specific ganglioside $\mathrm{GM}_{2}$ results in the alteration of the podocytes function [46].

Several intracellular and extracellular metabolic pathways and proteins contribute to the modification of SL pattern in DRM. By the comparison of the expression of the main sialytransferases involved in the SL biosynthesis and of the sialidases Neu1, Neu2, Neu3 and Neu4 we did not find statistically significative differences among these cell lines. These

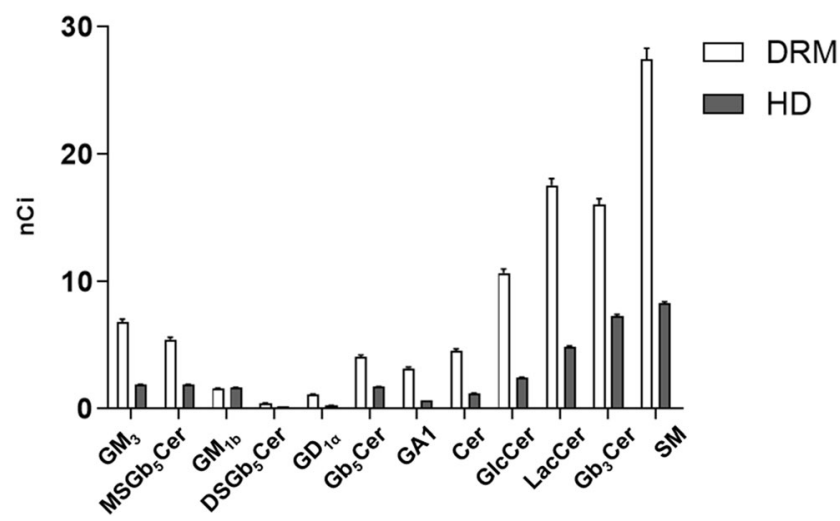

Fig. 6 Sphingolipid distribution among lipids rafts and detergentsoluble membrane fractions obtained from human podocytes. Cell sphingolipids were metabolically labelled at the steady state with $\left[1-{ }^{3} \mathrm{H}\right]$ sphingosine and lipid rafts (DRM) and high-density fraction (HD) were separated after cell lysis with $1 \%$ TX 100 at $4{ }^{\circ} \mathrm{C}$ followed by ultracentrifugation on a discontinuous sucrose gradient. Radioactive lipids were extracted, separated with HPTLC, visualized by digital autoradiography and quantified with M3 software. In the graphs, the data were reported as $\mathrm{nCi}$ associated to each lipid. Gangliotetraosylceramide (GA1), globotriaosylceramide $\left(\mathrm{Gb}_{3} \mathrm{Cer}\right)$, globopentaosylceramide $\left(\mathrm{Gb}_{5} \mathrm{Cer}\right)$, monosialoglobopentaosylceramide $\left(\mathrm{MSGb}_{5} \mathrm{Cer}\right)$, disialo-globopentaosylceramide (DSGb ${ }_{5} \mathrm{Cer}$ ), ceramide (Cer), glucosylceramide (GlcCer), lactosylceramide (LacCer), sphingomyelin (SM). $p<0.0005$

data together with those obtained by the analysis of the glycohydrolases in total cell lysate and at the plasma membrane level suggest that APOL1 probably interfere with the cellular trafficking of the SL and of their metabolic enzymes rather than acting on the general metabolic machinery [23]. A specific role of the intracellularly expressed APOL1 protein in HP is still under investigation, however, it is enriched in the plasma membrane and in Rab5 expressing endosomal vesicles [21]. Additionally, expression of APOL1 in HP increases upon cytokines' stimulation such as IFN- $\gamma$ and TNF- $\alpha$, thus indicating its role in the in anti-viral response [47]. Overexpression of all APOL1 proteins in HPs caused lysosomal swelling and cell death, with a more marked effect and a lower concentration threshold for the G1 and G2 risk Vs, compared to the nonrisk WT-APOL1 [18]. The present study sought to examine the APOL1 polymorphism-dependent modification of SLs in HPs. We have found that the overexpression of APOL1 protein in HPs induces several changes in the SLs composition. In particular, the overexpressing of APOL1 risk Vs are characterized by an enrichment in lipid rafts of $\mathrm{Gb}_{3} \mathrm{Cer}$ and $\mathrm{DSGb}_{5} \mathrm{Cer}$, while $\mathrm{Cer}$, LacCer, $\mathrm{GM}_{3}, \mathrm{GD}_{1 \alpha}, \mathrm{Gb}_{5} \mathrm{Cer}$, and $\mathrm{GA} 1$ decrease.

Importantly, we found that the expression of G1, compared to WT APOL1, induces a general reduction of all species of SLs, with the exception of SM. Differently, in the case of the expression of the specific G2 APOL1, we found a decreased content of Cer, GlcCer, LacCer, $\mathrm{GM}_{3}, \mathrm{GA} 1, \mathrm{~Gb}_{3} \mathrm{Cer}$, and $\mathrm{Gb}_{5} \mathrm{Cer}$; whereas, $\mathrm{GD}_{1 \alpha}$ and $\mathrm{DSGb}_{5}$ Cer are increased when compared to WT. These evidence let to speculate on a close correlation between APOL1-Vs G1/G2 and HIV internalization in HPs that could be responsible for an increased risk of developing $\operatorname{HIVAN}[7,8,30]$. 
Fig. 7 Effects of the overexpression of APOL1 WT, G1 and G2 Vs on the ganglioseries content of lipid rafts. Cell sphingolipids were metabolically labelled at the steady state with $\left[1-{ }^{3} \mathrm{H}\right]$ sphingosine and lipid rafts (DRM) and high-density fraction (HD) were separated after cell lysis with $1 \%$ TX 100 at $4{ }^{\circ} \mathrm{C}$ followed by ultracentrifugation on a discontinuous sucrose gradient. Radioactive lipids were extracted, separated with HPTLC, visualized by digital autoradiography and quantified with M3 software. Data are expressed as percentage with respect to Mock cells. Monosialosyl-

diexosylganglioside $\left(\mathrm{GM}_{3}\right)$, monosialosyl-

tetraexosylganglioside $\left(\mathrm{GM}_{1 \mathrm{~b}}\right)$, disialosyl-tetraexosylganglioside $\left(\mathrm{GD}_{1 \alpha}\right)$, gangliotetraosylceramide (GA1). $* * p<0.005$ vs Mock, *** $p<0.0005$ vs Mock, ${ }^{\circ} p<0.005$ vs WT, ${ }^{\circ \circ} \mathrm{p}<0.0005$ vs WT, \#\# $\mathrm{p}<0.005$ vs $\mathrm{G} 1$, \#\# $\mathrm{p}<0.0005$ vs G1

\section{Ganglio-series}

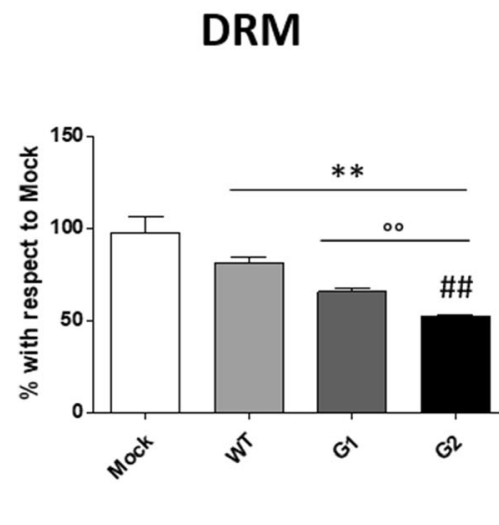

$\mathrm{GM}_{3}$

$\mathrm{GM}_{1 \mathrm{~b}}$

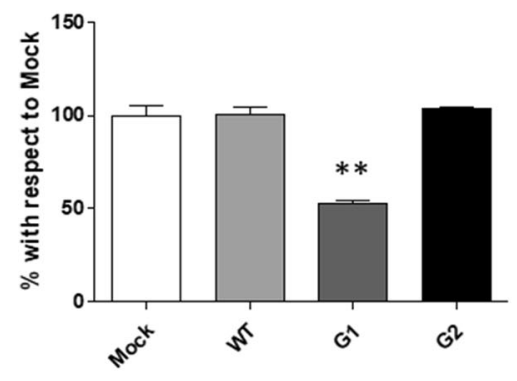

$\mathrm{GD}_{1 \alpha}$

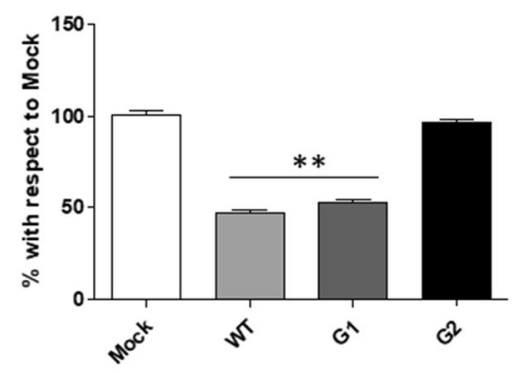

GA1

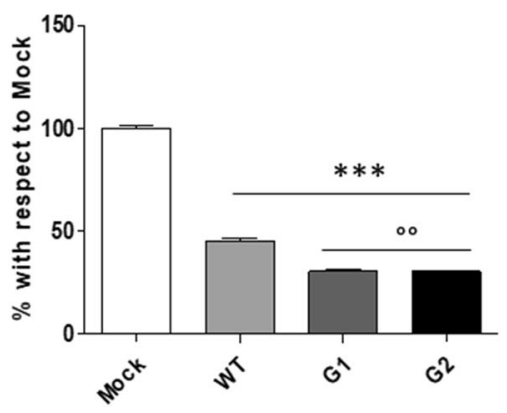

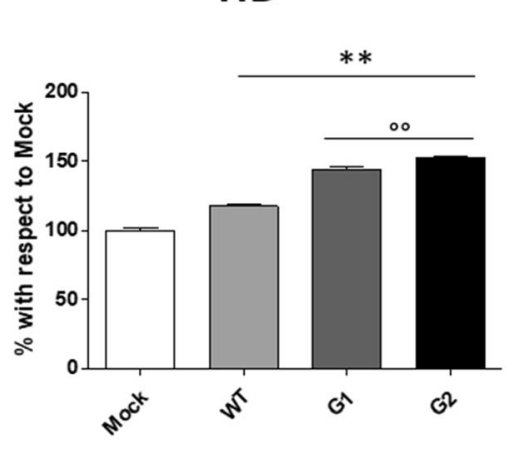
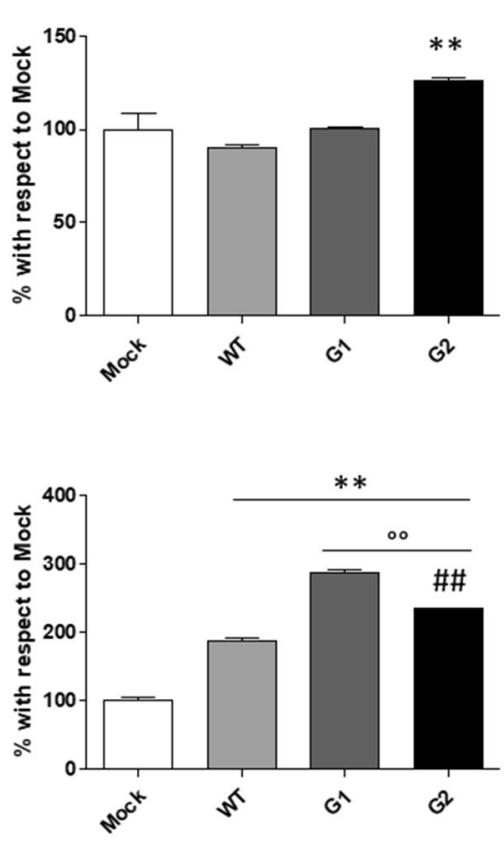

HD

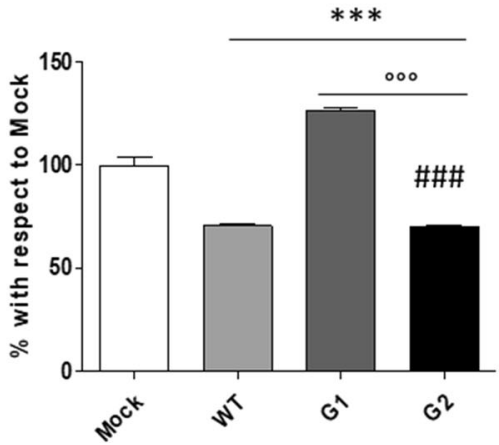

\section{Conclusions}

Taken together, our data suggest that APOL1 is an important player in the definition of the plasma membrane SL composition, in particular within lipids rafts. In addition, since lipids rafts are direct PM player involved in HIV internalization, the alteration of their SL profile due to the expression of APOL1 G1 or G2 Vs could be responsible for the onset of HIVAN. However, further studies are necessary to dissect the specific mechanism of action of APOL1 as SL modulators as well as to correlate the alteration in podocytes SL pattern with the onset of APOL1-related pathologies. 
Fig. 8 Effects of the overexpression of APOL1 WT, G1 and G2 Vs on the globoseries content of lipid rafts. Cell sphingolipids were metabolically labelled at the steady state with $\left[1-{ }^{3} \mathrm{H}\right]$ sphingosine and lipid rafts (DRM) and high-density fraction (HD) were separated, after cell lysis in $1 \%$ TX 100 at $4{ }^{\circ} \mathrm{C}$ followed by ultracentrifugation on a discontinuous sucrose gradient. Radioactive lipids were extracted, separated with HPTLC, visualized by digital autoradiography and quantified with M3 software. Data are expressed as percentage with respect to Mock cells. Globotriaosylceramide $\left(\mathrm{Gb}_{3} \mathrm{Cer}\right)$,

globopentaosylceramide ( $\left.\mathrm{Gb}_{5} \mathrm{Cer}\right)$, monosialosylglobopentaosylceramide (MSGb $\left.{ }_{5} \mathrm{Cer}\right)$, disialosylglobopentaosylceramide (DSGb ${ }_{5}$ Cer). $* p<0.05$, ${ }^{* *} p<0.005, * * * p<0.0005,{ }^{\circ} \mathrm{p}$ $<0.005$ vs WT, ${ }^{\circ} \mathrm{p}<0.005$ vs WT, ${ }^{\circ \circ} \mathrm{p}<0.0005$ vs WT, \#\# $\mathrm{p}$ $<0.005$ vs G1, \#\# p $<0.005$ vs G1
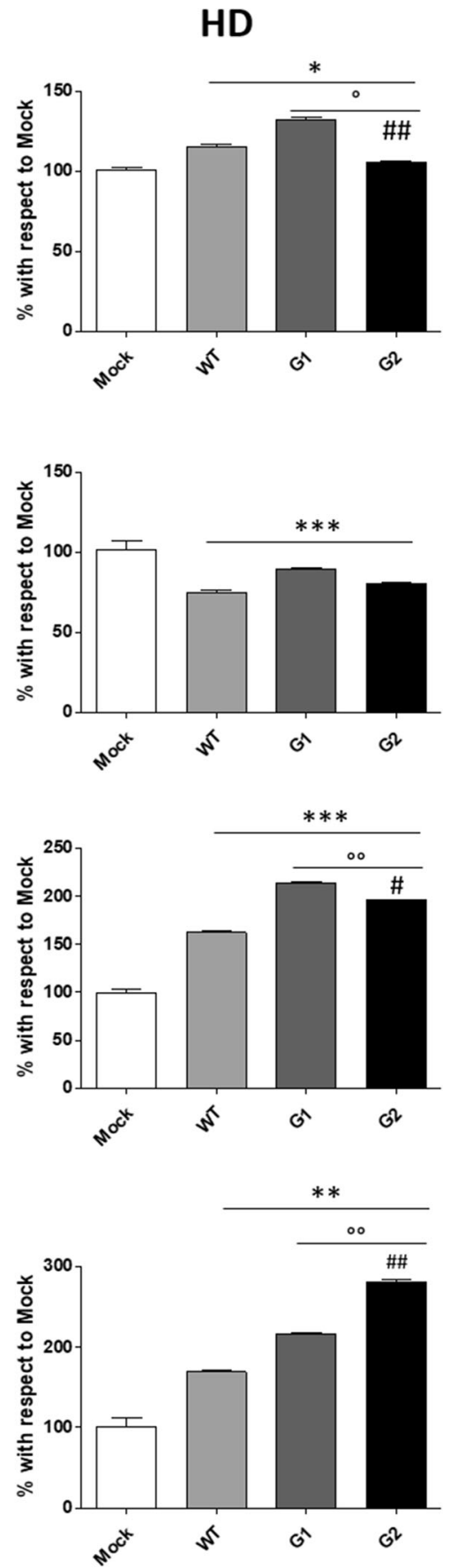

Globo-series
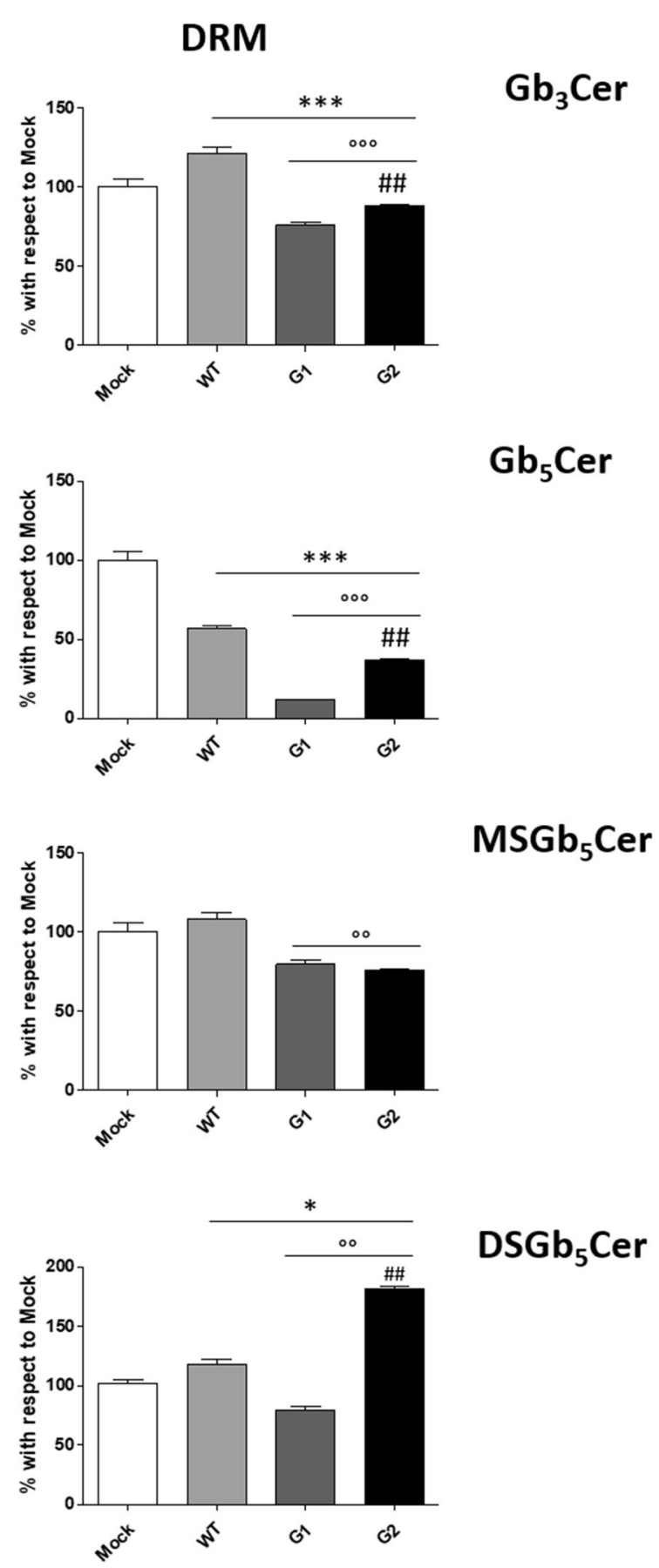

$\mathrm{Gb}_{3} \mathrm{Cer}$

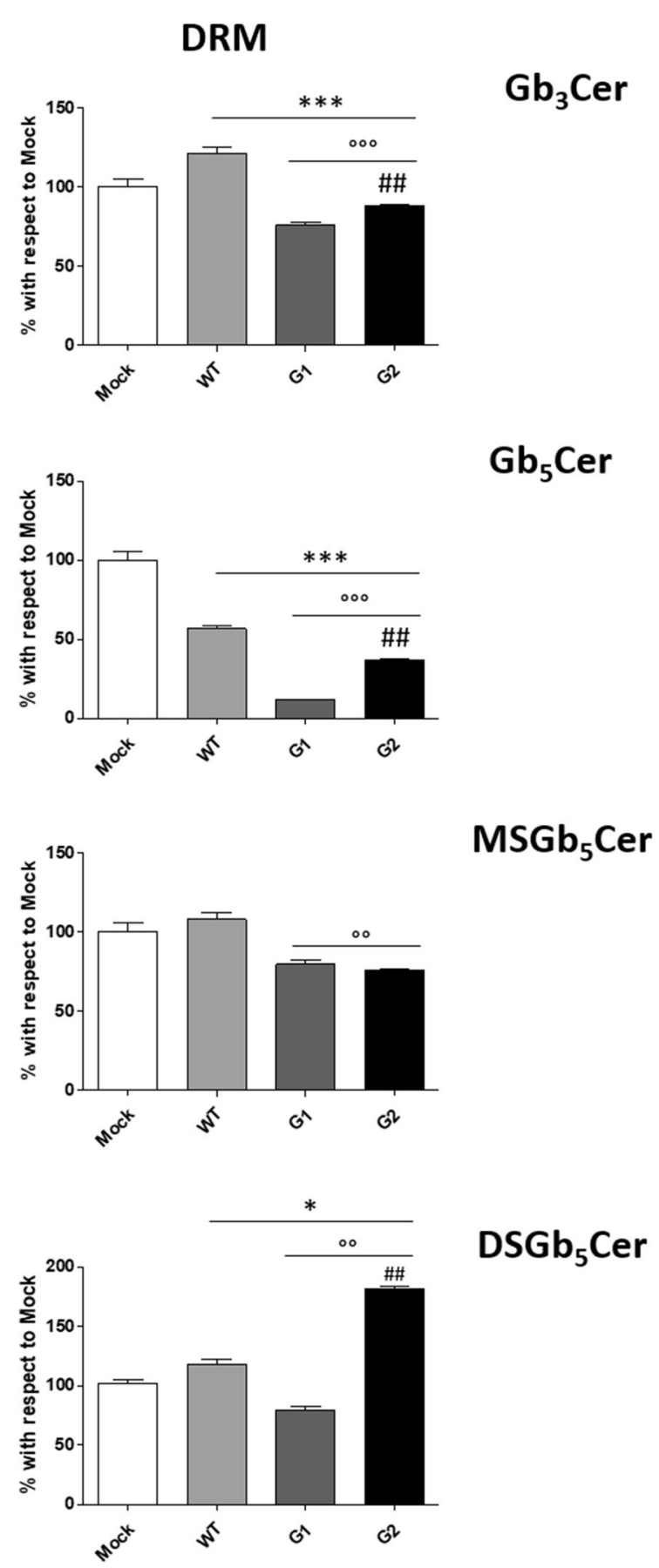

$\mathrm{Gb}_{5} \mathrm{Cer}$

$\mathrm{MSGb}_{5} \mathrm{Cer}$

$\mathrm{DSGb}_{5} \mathrm{Cer}$

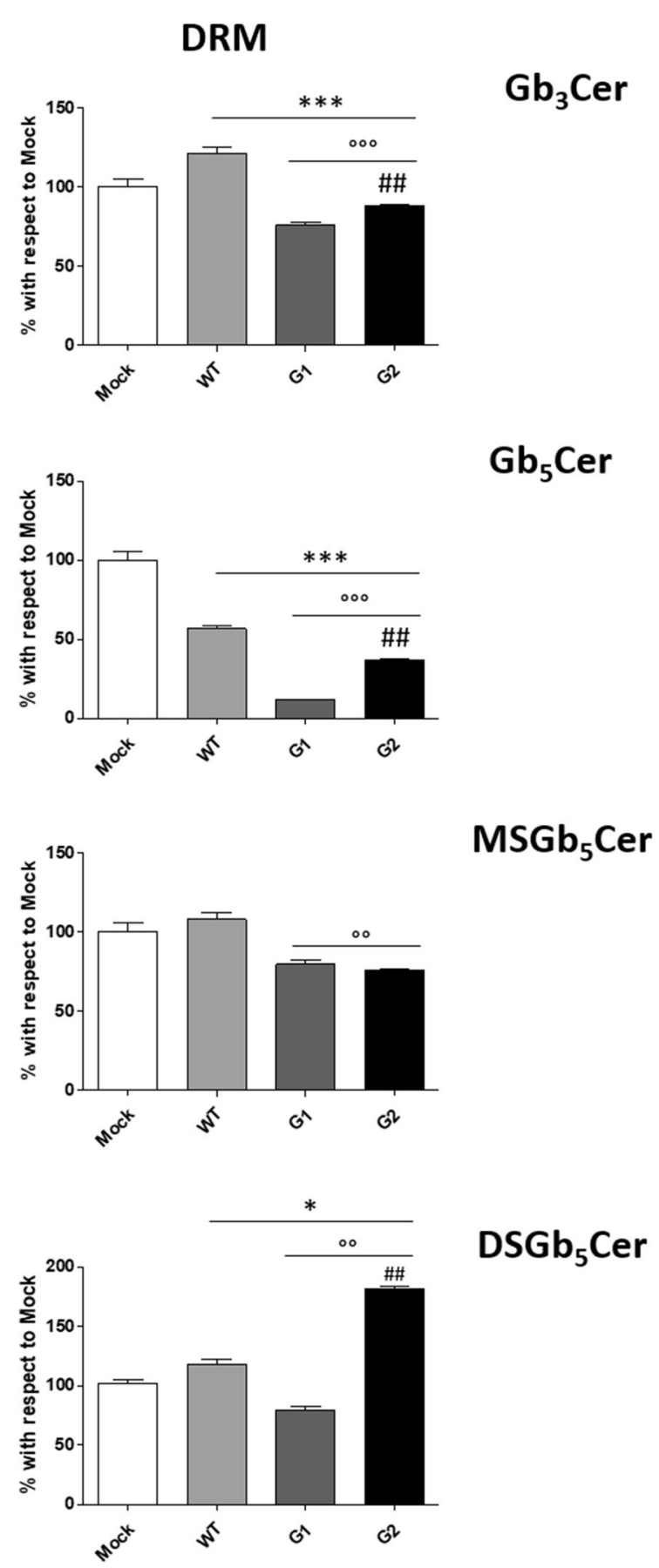

DRM

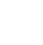

\section{Methods}

\section{Cell culture}

Conditionally immortalized human podocytes (HPs) were developed and cultured as described in Saleem M.A. et al. [34]. Stable G0/G1/G2 APOL1 transfected HPs were generated by retroviral infection as described [21]. Briefly, the open reading frame APOL1 (G0, G1, 
Fig. 9 Effects of the overexpression of APOL1 WT, G1 and G2 Vs on the other sphingolipids content of lipid rafts. Cell sphingolipids were metabolically labelled at the steady state with

$\left[1-{ }^{3} \mathrm{H}\right]$ sphingosine and lipid rafts (DRM) and high- $\alpha$ density fraction (HD) were separated after cell lysis in $1 \%$ TX 100 at $4{ }^{\circ} \mathrm{C}$ followed by ultracentrifugation on a discontinuous sucrose gradient. Radioactive lipids were extracted, separated with HPTLC, visualized by digital autoradiography and quantified with M3 software. Data are expressed as percentage with respect to Mock cells. Ceramide (Cer), glucosylceramide (GlcCer), lactosylceramide (LacCer), sphingomyelin (SM). $* * \mathrm{p}<$ $0.005, * * * \mathrm{p}<0.0005,{ }^{\circ} \mathrm{p}<0.005$ vs WT, ${ }^{\circ} \mathrm{p}<0.005$ vs WT, ${ }^{\circ}{ }^{\circ} \mathrm{p}$ $<0.0005$ vs WT, \# p <0.005 vs G1, \#\# p <0.005 vs G1
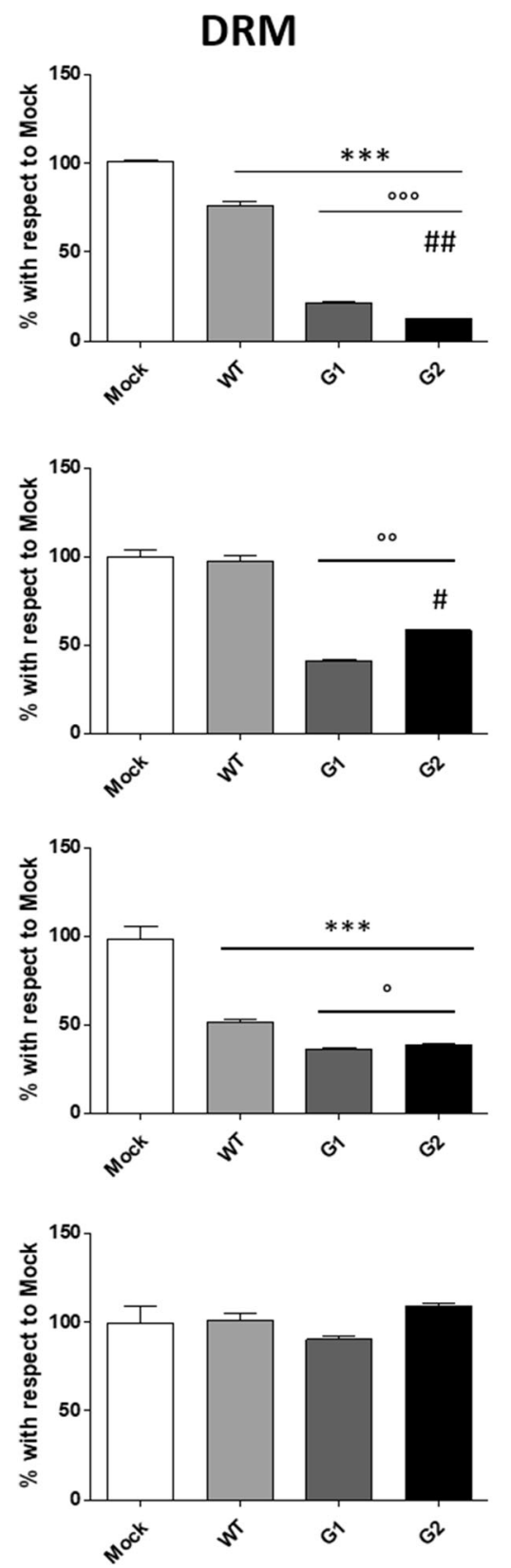

Cer

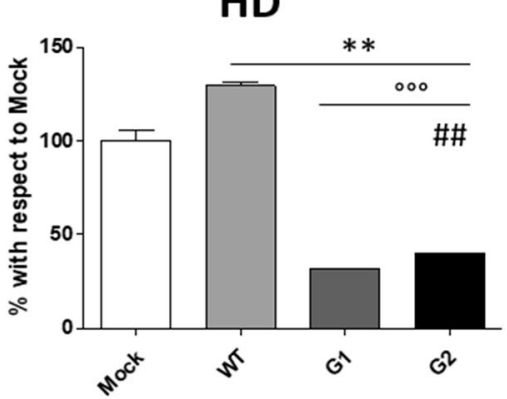

GlcCer

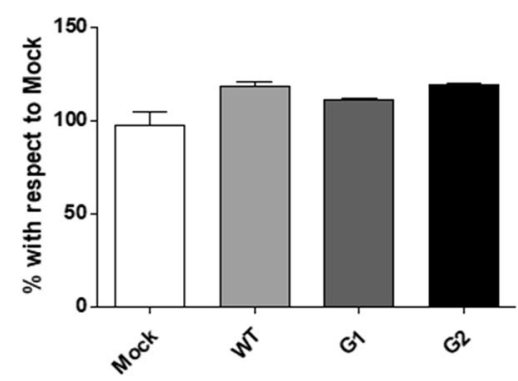

LacCer

SM
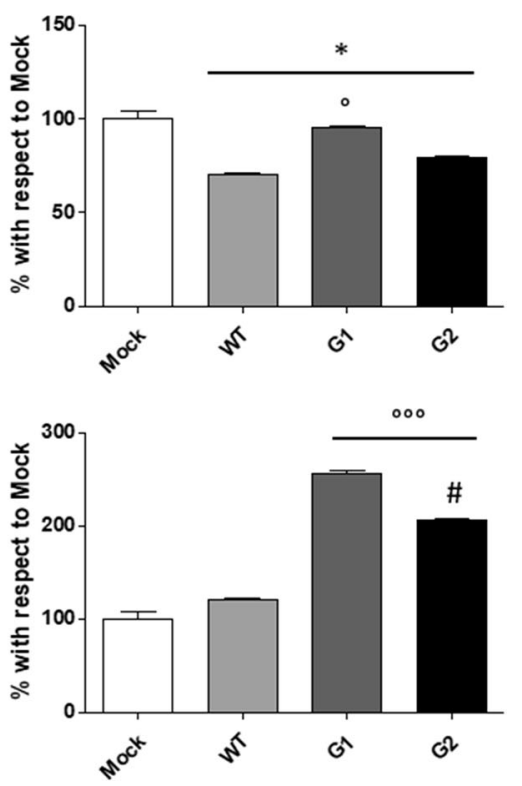

\section{Determination of protein content by DC protein assay}

Samples protein content was determined through DC protein assay (Bio-Rad) following the manufacturer indications.

\section{SDS-PAGE and Western blotting}

Aliquots of cell lysates corresponding to the same amount of proteins were resuspended in Laemmli buffer and denaturated for $10 \mathrm{~min}$ at $100{ }^{\circ} \mathrm{C}$. SDS-PAGE was performed using a
Miniprotean II unit, produced by Bio-Rad using a gradient gel of 4-20\% of poly-acrylamide (Bio-Rad).

After electrophoresis separation, proteins were transferred into PVDF membrane that were in 5\% skim milk in TBS-T $0,01 \%$. Then the PVDF was washed three times with TBS-T $0.01 \%$ and incubated overnight at $4{ }^{\circ} \mathrm{C}$ with the appropriate primary antibodies. Caveolin-1(BD Transduction Laboratories) and Calnexin (Cell Signalling) antibody were used at the final dilution of 1:1000. At the end, the PVDFs were washed three times with TBS-T $0,1 \%$ and incubated for $1 \mathrm{~h}$ at RT with the appropriate secondary antibodies. The 
membranes were then washed again for three times and the peroxidase activity was assessed through incubation with horseradish peroxidase substrate (Westar Cyanagen). The chemiluminescent signal was revealed using a Mini HD9 (UviTec, Cambridge) and analyzed by Nine Alliance mini HD9 software.

\section{Treatment of cells with $\left[1-{ }^{3} \mathrm{H}\right]$ sphingosine}

$\left[1-{ }^{3} \mathrm{H}\right]$ sphingosine dissolved in methanol is transferred into a sterile glass tube and dried under a nitrogen stream and the residue then dissolved in an appropriate volume of prewarmed $\left(37^{\circ} \mathrm{C}\right)$ cell culture medium to obtain a final concentration of $(3 \times 10)^{-8} \mathrm{M}$. Cells are incubated for a $2 \mathrm{~h}$ pulse and, after that, the medium was removed and replaced with fresh medium without radioactive sphingosine for the $48 \mathrm{~h}$. At the end of the chase periods, cells were collected for the SLs analyses and DRM preparation [48, 49].

\section{DRM preparation}

Cells were lysed in lysis buffer (1\% Triton X-100, $10 \mathrm{mM}$ Tris buffer, pH 7.5, $150 \mathrm{mM} \mathrm{NaCl}, 5 \mathrm{mM}$ EDTA, $1 \mathrm{mM} \mathrm{Na}_{3} \mathrm{VO}_{4}$, $1 \mathrm{mM}$ phenylmethylsulfonyl fluoride, and 75 milliunits $/ \mathrm{ml}$ aprotinin, 3-4 mg of cell protein/ml) and Dounce homogenized (10 strokes, tight). Cell lysate is centrifuged (5 min, $1300 \times \mathrm{g}$ ) to remove nuclei and cellular debris. The postnuclear fraction is mixed with an equal volume of $85 \%$ sucrose $(w / v)$ in $10 \mathrm{mM}$ Tris buffer ( $\mathrm{pH} 7.5$ ), placed at the bottom of a discontinuous sucrose concentration gradient $(30-5 \%)$ in the same buffer, and centrifuged $(17 \mathrm{~h}, 200,000 \times \mathrm{g})$ at $4{ }^{\circ} \mathrm{C}$. After ultracentrifugation, eleven fractions are collected starting from the top of the tube $[50,51]$.

\section{Analysis of radioactive sphingolipids}

Radioactive lipids associated with total cell lysates, DRM and high density (HD) fractions were extracted twice with chloroform/methanol 2:1 (v:v) and chloroform/methanol/water 20:10:1 (v:v); the total lipid extracts were subjected to a two-phase partitioning by adding $20 \%$ water to the lipid extract accordingly to $[52,53]$. The organic phases were then submitted to alkaline treatment followed by partitioning to remove glycerophospholipids. The radioactivity associated with aqueous and organic phases was evaluated by liquid scintillation. $\left[{ }^{3} \mathrm{H}\right]$ sphingolipids were analyzed by HPTLC (high performance thin layer chromatography) using glass plates silica gel 60 (Merck) as stationary phase and the solvent systems used as mobile phase were: first run in chloroformmethanol 2:1, followed by a second run with the solvent systems chloroform-methanol- $0.2 \%$ aqueous $\mathrm{CaCl}_{2}, 50: 42: 11$ (v:v:v), for the polar sphingolipids; a run with the solvent systems chloroform-methanol-water 110:40:6 (v:v:v) for the neutral lipids. Polar sphingolipids are also separated bidimensional thin layer chromatography using: a first run with the solvent systems chloroform-methanol- $0.2 \%$ aqueous $\mathrm{CaCl}_{2}, 50: 42: 11$ (v:v) followed by a second orthogonal run in chloroform-methanol- $0.2 \%$ aqueous $\mathrm{CaCl}_{2}, 50: 42: 11$ (v:v). Radioactive lipids were visualized by digital autoradiography ( ${ }^{\mathrm{T}}$ Racer BetaImager; BioSpace Laboratory, Nesles la Vallée, France) and quantified using BioSpace Lab's M3 Vision software. Identification of lipids after separation was assessed by comigration with radioactive lipid standards.

\section{Analyses of endogenous sphingolipids}

For endogenous sphingolipid pattern, total lipid extract is subjected to a two-phase partitioning as previously described [54] resulting in the separation of an aqueous phase containing polar sphingolipids and in an organic phase containing all neutral lipids. Phospholipids present in the organic phase are then removed by a mild alkaline treatment; both aqueous phase and alkali-treated organic phase are used for HPTLC as described before. Representative images were reported in supplementary Fig. 4.

In addition, part of the samples was used for mass analyses.MS analyses are carried out using a Thermo Quest Finnigan LCQDeca ion trap mass spectrometer (FINNIGAN MAT, San Jose, CA) equipped with an ESI ion source and an Xcalibur data system and a TSP P4000 quaternary pump HPLC. Separations of all SLs (sphingolipids) are obtained on a $5 \mu \mathrm{m}, 250 \times 4 \mathrm{~mm}$ LiChrospher $100 \mathrm{RP} 8$ column (Merck).

Elution of $\mathrm{Gb}_{5} \mathrm{Cer}$ and its sialylated forms, and gangliosides molecular species is carried out, at a flow rate of $0.5 \mathrm{ml} / \mathrm{min}$, using a gradient formed by the solvent system A, consisting of $\mathrm{CH}_{3} \mathrm{CN} / 5 \mathrm{mM}$ ammonium acetate buffer, pH 7 (15:85 by volume) and solvent $\mathrm{B}$ containing $\mathrm{CH}_{3} \mathrm{CN} /$ $\mathrm{H}_{2} \mathrm{O}$ ( $85: 15$ by volume). The gradient is linear from $30: 70$ to $20: 80$, by volume, of $\mathrm{A}: \mathrm{B}$, over $25 \mathrm{~min}$, followed by a $5 \mathrm{~min}$ gradient from 20:80 to 0:100, by volume, of $A: B$, followed by 15 min of isocratic condition at $100 \%$ of B.

Elution of SM, Cer and other neutral SLs molecular species is carried out, at a flow rate of $0.5 \mathrm{ml} / \mathrm{min}$, with a gradient formed by the solvent system A, consisting methanol/water (90:10 by vol), and solvent system B, consisting of methanol, both containing $5 \mathrm{mM}$ ammonium acetate. The gradient elution program is as follows: $5 \mathrm{~min}$ with solvent $\mathrm{A} ; 5 \mathrm{~min}$ with a linear gradient from $100 \%$ solvent A to $100 \%$ solvent B; 15 min with $100 \%$ solvent $\mathrm{B} ; 5$ min with a linear gradient from $100 \%$ solvent B to $100 \%$ methanol. Methanol is also used to wash the column for $10 \mathrm{~min}$, followed by equilibration procedure with solvent A for $15 \mathrm{~min}$.

Optimum conditions for $\mathrm{Gb}_{5} \mathrm{Cer}$ and its sialylated forms, and ganglioside molecular species MS analyses include sheath gas flow of 70 arbitrary units, auxiliary gas flow of 10 arbitrary units, spray voltage of $4 \mathrm{kV}$, capillary voltage of $-42 \mathrm{~V}$, 
capillary temperature of $260{ }^{\circ} \mathrm{C}$, fragmentation voltage (used for collision induced dissociation) of 40-80\%. Mass spectra are acquired over a range m/z 200-2000.

Optimum conditions for SM, Cer and other neutral SLs molecular species MS analyses include sheath gas flow of 50 arbitrary units, spray voltage of $4 \mathrm{kV}$, capillary voltage of $-47 \mathrm{~V}$, capillary temperature of $260^{\circ} \mathrm{C}$, fragmentation voltage (used for collision induced dissociation) of 40-60\%. Mass spectra are acquired over a m/z range 200-1600.

For all experiments, source ion optics are adjusted to accomplish desolvation of ions while minimizing fragmentation.

\section{Sialidase treatment}

For sialidase treatment, aliquots of polar sphingolipids, in a total volume of $0,1 \mathrm{ml}$ of aqueous solution, were incubated for $20 \mathrm{~h}$ at $37^{\circ} \mathrm{C}$ with 0,02 unit of Vibrio cholera sialidase; then the samples were dried and used for HPTLC.

\section{Evaluation of enzymatic activities in cell lysates}

The enzymatic activities associated with total cell lysates were determined using a previously described method based on 4Methylumbelliferone (MUB)-derived fluorogenic substrates [49, 55]: 4-methylumbelliferyl $\beta$-d-glucopyranoside (MUB- $\beta$-Glc) for $\beta$-glucocerebrosidase (GCase and NLGase), 4-methylumbelliferyl $\beta$-d-galactopyranoside (MUB- $\beta$-Gal) for $\beta$-galactosidase, 4-methylumbelliferyl $\alpha$ d-galactopyranoside (MUB- $\alpha$-Gal) for $\alpha$-galactosidase and 4-methylumbelliferyl N-acetyl- $\beta$-d-glucuronide (MUG) for $\beta$-hexosaminidase (all from Glycosynth, Warrington, United Kingdom). In order to distinguish between GCase and NLGase activity, cell lysates were preincubated for $30 \mathrm{~min}$ at room temperature in McIlvaine buffer ( $\mathrm{pH}$ 6) with $5 \mathrm{nM}$ AMP-DNM (adamantane-pentyl-dNM; N-(5-adamantane-1yl-methoxy-pentyl) deoxynojirimycin), a specific inhibitor of NLGase, or $1 \mathrm{mM}$ CBE (conduritol-B-epoxide) (Sigma), a specific inhibitor of CGase. At the end of preincubation, the reaction was started with the addition of $25 \mu$ of MUB- $\beta-$ Glc at the final concentration of $6 \mathrm{mM}$. To measure $\beta$-galactosidase, $\alpha$-galactosidase, and $\beta$-hexosaminidase aliquots of cell lysates were incubated with $25 \mu$ l of McIlvaine buffer (pH 5.2) containing the specific florigenic substrates at the final concentration of $500 \mu \mathrm{M}$. Then water was added to reach the final volume of $100 \mu \mathrm{l}$. At different time points, the reaction mixtures were blocked by adding 19 volumes of $0.25 \mathrm{M}$ glycine (pH 10.7; MilliporeSigma). Standard free MUB were used to quantify the substrate hydrolysis. Enzymatic activity is expressed as picomoles of product per milligram of cell proteins per hour.

\section{Evaluation of enzymatic activity on the surface of living cells}

Cells were plated in 96-well microplates at a density of 20,000 cells/well, and plasm membrane-associated activities of GCase, NLGase, $\alpha$-galactosidase, $\beta$-galactosidase, and $\beta$ hexosaminidase were assessed in these cells by a high throughput cell lived-based assay as previously described $[49,55]$. To distinguish between GCase and NLGase activities, cells were preincubated for $30 \mathrm{~min}$ at room temperature in DMEM-F12 without phenol red (Thermo Fisher Scientific) containing $5 \mathrm{nM}$ AMP-DNM or $1 \mathrm{mM} \mathrm{CBE}$, respectively [56]. Activities were assayed using the artificial MUB- $\alpha$-Gal for $\alpha$-galactosidase, MUB- $\beta$-Gal for $\beta$-galactosidase, MUG for $\beta$-hexosaminidase, and MUB- $\beta$-Glc for GCase and NLGase. The fluorogenic substrates were solubilized in DMEM-F12 without phenol red at $\mathrm{pH}$ 6, with final concentrations of $250 \mu \mathrm{M}, 250 \mu \mathrm{M}, 1 \mathrm{mM}$, and $6 \mathrm{mM}$, respectively. Aliquots of medium $(10 \mu \mathrm{l})$ were analysed at different time points by a Victor microplate reader (PerkinElmer), after the addition of $190 \mu \mathrm{l}$ of $0.25 \mathrm{M}$ glycine ( $\mathrm{pH}$ 10.7). Standard free MUB was used to construct calibration curves and quantify substrate hydrolysis. Enzymatic activity is expressed as picomoles of product per $10^{6}$ cells per hour.

\section{Whole-Transcriptome data analysis}

Raw sequencing single-end reads were processed for quality check using FASTQC (v0.11.5) (http://www. bioinformatics. babraham.ac.uk/projects/fastqc). Raw reads were mapped to the human reference genome (Gencode GRCh38 v24 primary assembly) using STAR aligner (v2.5.2a) [57]. Gencode annotation v24 gene transfer file (GTF) was used as reference gene annotation file for alignment. Aligned Bam data were sorted and indexed using SAMtools [58]. Gene expression was quantified by using the quantmode GeneCounts option of the STAR aligner; the counts produced using this approach coincide with those produced by HTSeq-count [59] using default parameters. The statistical analysis was performed by using DESeq2 package [60], testing (Wald Test) group vs group accordingly to experimental design. A threshold of 0 . 05 was applied to False Discovery Rate (FDR) adjusted $p$ values in order to select the differentially expressed genes (DEGs) to use in downstream analysis. Exploration data analysis (clustering and principal component analysis - PCA) was performed using built-in functions of the DESeq2 package.

\section{Statistical analysis}

All the experiments were performed in triplicate and repeated $\geq 3$ times. Data are presented as the means \pm S.D. and were tested for significance with Student's $t$ test or one-way 
ANOVA using GraphPad Prism 8 software (GraphPad Software, La Jolla, CA, USA).

Acknowledgments This work was supported by grants RO1DK118017 (PCS) from National Institutes of Health (NIH), Bethesda, MD; we thank Karl Skorecki for the generous donation of the podocytes stable overexpressing the different variants of APOL1.

Funding Open access funding provided by Università degli Studi di Milano within the CRUI-CARE Agreement. This work was supported by grants RO1DK118017 (PCS) from National Institutes of Health (NIH), Bethesda, MD.

Data availability we declare that all the row data are available.

\section{Compliance with ethical standards}

Conflict of interest The authors declare no conflict of interest. The funders had no role in the design of the study; in the collection, analyses, or interpretation of data; in the writing of the manuscript, or in the decision to publish the results.

Ethical approval not applicable.

Consent to participate not applicable.

Consent for publication all the authors consent to the publication of the manuscript.

Code availability The softwares used for: writing the paper (Microsoft Word), statistical analyses and graphs (GaphPad Prism 8), and for the figures formation (Microsoft PowerPoint) were licensed to the Host Institution: Department of Medical Biotechnology and Translational Medicine.

Open Access This article is licensed under a Creative Commons Attribution 4.0 International License, which permits use, sharing, adaptation, distribution and reproduction in any medium or format, as long as you give appropriate credit to the original author(s) and the source, provide a link to the Creative Commons licence, and indicate if changes were made. The images or other third party material in this article are included in the article's Creative Commons licence, unless indicated otherwise in a credit line to the material. If material is not included in the article's Creative Commons licence and your intended use is not permitted by statutory regulation or exceeds the permitted use, you will need to obtain permission directly from the copyright holder. To view a copy of this licence, visit http://creativecommons.org/licenses/by/4.0/.

\section{References}

1. Duchateau, P.N., Pullinger, C.R., Orellana, R.E., Kunitake, S.T., Naya-Vigne, J., O'Connor, P.M., Malloy, M.J., Kane, J.P.: Apolipoprotein L, a new human high density lipoprotein apolipoprotein expressed by the pancreas. Identification, cloning, characterization, and plasma distribution of apolipoprotein L. J Biol Chem. 272(41), 25576-25582 (1997). https://doi.org/10.1074/jbc. 272.41.25576

2. Duchateau, P.N., Movsesyan, I., Yamashita, S., Sakai, N., Hirano, K., Schoenhaus, S.A., O'Connor-Kearns, P.M., Spencer, S.J., Jaffe,
R.B., Redberg, R.F., Ishida, B.Y., Matsuzawa, Y., Kane, J.P., Malloy, M.J.: Plasma apolipoprotein L concentrations correlate with plasma triglycerides and cholesterol levels in normolipidemic, hyperlipidemic, and diabetic subjects. J. Lipid Res. 41(8), 1231$1236(2000)$

3. Vanhamme, L., Paturiaux-Hanocq, F., Poelvoorde, P., Nolan, D.P., Lins, L., Van Den Abbeele, J., Pays, A., Tebabi, P., Van Xong, H., Jacquet, A., Moguilevsky, N., Dieu, M., Kane, J.P., De Baetselier, P., Brasseur, R., Pays, E.: Apolipoprotein L-I is the trypanosome lytic factor of human serum. Nature. 422(6927), 83-87 (2003). https://doi.org/10.1038/nature01461

4. Molina-Portela, M.P., Samanovic, M., Raper, J.: Distinct roles of apolipoprotein components within the trypanosome lytic factor complex revealed in a novel transgenic mouse model. J. Exp. Med. 205(8), 1721-1728 (2008). https://doi.org/10.1084/jem. 20071463

5. Perez-Morga, D., Vanhollebeke, B., Paturiaux-Hanocq, F., Nolan, D.P., Lins, L., Homble, F., Vanhamme, L., Tebabi, P., Pays, A., Poelvoorde, P., Jacquet, A., Brasseur, R., Pays, E.: Apolipoprotein L-I promotes trypanosome lysis by forming pores in lysosomal membranes. Science. 309(5733), 469-472 (2005). https://doi.org/ 10.1126/science. 1114566

6. Thomson, R., Genovese, G., Canon, C., Kovacsics, D., Higgins, M.K., Carrington, M., Winkler, C.A., Kopp, J., Rotimi, C., Adeyemo, A., Doumatey, A., Ayodo, G., Alper, S.L., Pollak, M.R., Friedman, D.J., Raper, J.: Evolution of the primate trypanolytic factor APOL1. Proc. Natl. Acad. Sci. U. S. A. 111(20), E2130-E2139 (2014). https://doi.org/10.1073/pnas.1400699111

7. Medapalli, R.K., He, J.C., Klotman, P.E.: HIV-associated nephropathy: pathogenesis. Curr. Opin. Nephrol. Hypertens. 20(3), 306311 (2011). https://doi.org/10.1097/MNH.0b013e328345359a

8. Kopp, J.B., Heymann, J., Winkler, C.A.: APOL1 renal risk variants: fertile soil for HIV-associated nephropathy. Semin. Nephrol. 37(6), 514-519 (2017). https://doi.org/10.1016/j.semnephrol.2017. 07.004

9. Mikulak, J., Singhal, P.C.: HIV-1 and kidney cells: better understanding of viral interaction. Nephron Exp Nephrol. 115(2), e15e21 (2010). https://doi.org/10.1159/000312882

10. Rednor, S.J., Ross, M.J.: Molecular mechanisms of injury in HIVassociated nephropathy. Front Med (Lausanne). 5, 177 (2018). https://doi.org/10.3389/fmed.2018.00177

11. Mikulak, J., Teichberg, S., Arora, S., Kumar, D., Yadav, A., Salhan, D., Pullagura, S., Mathieson, P.W., Saleem, M.A., Singhal, P.C.: DC-specific ICAM-3-grabbing nonintegrin mediates internalization of HIV-1 into human podocytes. Am J Physiol Renal Physiol. 299(3), F664-F673 (2010). https://doi.org/10. 1152/ajprenal.00629.2009

12. Wan, G., Zhaorigetu, S., Liu, Z., Kaini, R., Jiang, Z., Hu, C.A.: Apolipoprotein L1, a novel Bcl-2 homology domain 3-only lipidbinding protein, induces autophagic cell death. J. Biol. Chem. 283(31), 21540-21549 (2008). https://doi.org/10.1074/jbc. M800214200

13. Zhaorigetu, S., Wan, G., Kaini, R., Jiang, Z., Hu, C.A.: ApoL1, a $\mathrm{BH} 3$-only lipid-binding protein, induces autophagic cell death. Autophagy. 4(8), 1079-1082 (2008). https://doi.org/10.4161/auto. 7066

14. Ma, L., Shelness, G.S., Snipes, J.A., Murea, M., Antinozzi, P.A., Cheng, D., Saleem, M.A., Satchell, S.C., Banas, B., Mathieson, P.W., Kretzler, M., Hemal, A.K., Rudel, L.L., Petrovic, S., Weckerle, A., Pollak, M.R., Ross, M.D., Parks, J.S., Freedman, B.I.: Localization of APOL1 protein and mRNA in the human kidney: nondiseased tissue, primary cells, and immortalized cell lines. J. Am. Soc. Nephrol. 26(2), 339-348 (2015). https://doi.org/ 10.1681/ASN.2013091017 
15. Taylor, H.E., Khatua, A.K., Popik, W.: The innate immune factor apolipoprotein L1 restricts HIV-1 infection. J. Virol. 88(1), 592603 (2014). https://doi.org/10.1128/JVI.02828-13

16. Kumar, V., Ayasolla, K., Jha, A., Mishra, A., Vashistha, H., Lan, X., Qayyum, M., Chinnapaka, S., Purohit, R., Mikulak, J., Saleem, M.A., Malhotra, A., Skorecki, K., Singhal, P.C.: Disrupted apolipoprotein L1-miR193a axis dedifferentiates podocytes through autophagy blockade in an APOL1 risk milieu. Am J Physiol Cell Physiol. 317(2), C209-C225 (2019). https://doi.org/10.1152/ ajpcell.00538.2018

17. Kumar, V., Vashistha, H., Lan, X., Chandel, N., Ayasolla, K., Shoshtari, S.S.M., Aslam, R., Paliwal, N., Abbruscato, F., Mikulak, J., Popik, W., Atta, M.G., Chander, P.N., Malhotra, A., Meyer-Schwesinger, C., Skorecki, K., Singhal, P.C.: Role of Apolipoprotein L1 in human parietal epithelial cell transition. Am. J. Pathol. 188(11), 2508-2528 (2018). https://doi.org/10. 1016/j.ajpath.2018.07.025

18. Lan, X., Jhaveri, A., Cheng, K., Wen, H., Saleem, M.A., Mathieson, P.W., Mikulak, J., Aviram, S., Malhotra, A., Skorecki, K., Singhal, P.C.: APOL1 risk variants enhance podocyte necrosis through compromising lysosomal membrane permeability. Am J Physiol Renal Physiol. 307(3), F326-F336 (2014). https:// doi.org/10.1152/ajprenal.00647.2013

19. Lan, X., Wen, H., Lederman, R., Malhotra, A., Mikulak, J., Popik, W., Skorecki, K., Singhal, P.C.: Protein domains of APOL1 and its risk variants. Exp. Mol. Pathol. 99(1), 139-144 (2015). https://doi. org/10.1016/j.yexmp.2015.06.003

20. Lan, X., Wen, H., Saleem, M.A., Mikulak, J., Malhotra, A., Skorecki, K., Singhal, P.C.: Vascular smooth muscle cells contribute to APOL1-induced podocyte injury in HIV milieu. Exp. Mol. Pathol. 98(3), 491-501 (2015). https://doi.org/10.1016/j.yexmp. 2015.03.020

21. Mikulak, J., Oriolo, F., Portale, F., Tentorio, P., Lan, X., Saleem, M.A., Skorecki, K., Singhal, P.C., Mavilio, D.: Impact of APOL1 polymorphism and IL-1beta priming in the entry and persistence of HIV-1 in human podocytes. Retrovirology. 13(1), 63 (2016). https://doi.org/10.1186/s12977-016-0296-3

22. Hakomori Si, S.I.: The glycosynapse. Proc. Natl. Acad. Sci. U. S. A. 99(1), 225-232 (2002). https://doi.org/10.1073/pnas.012540899

23. Fornoni, A., Merscher, S., Kopp, J.B.: Lipid biology of the podocyte-new perspectives offer new opportunities. Nat Rev Nephrol. 10(7), 379-388 (2014). https://doi.org/10.1038/nrneph. 2014.87

24. Wei, C., Moller, C.C., Altintas, M.M., Li, J., Schwarz, K., Zacchigna, S., Xie, L., Henger, A., Schmid, H., Rastaldi, M.P., Cowan, P., Kretzler, M., Parrilla, R., Bendayan, M., Gupta, V., Nikolic, B., Kalluri, R., Carmeliet, P., Mundel, P., Reiser, J.: Modification of kidney barrier function by the urokinase receptor. Nat. Med. 14(1), 55-63 (2008). https://doi.org/10.1038/nm1696

25. Yamashita, T., Hashiramoto, A., Haluzik, M., Mizukami, H., Beck, S., Norton, A., Kono, M., Tsuji, S., Daniotti, J.L., Werth, N., Sandhoff, R., Sandhoff, K., Proia, R.L.: Enhanced insulin sensitivity in mice lacking ganglioside GM3. Proc. Natl. Acad. Sci. U. S. A. 100(6), 3445-3449 (2003). https://doi.org/10.1073/pnas. 0635898100

26. Jin, J., Sison, K., Li, C., Tian, R., Wnuk, M., Sung, H.K., Jeansson, M., Zhang, C., Tucholska, M., Jones, N., Kerjaschki, D., Shibuya, M., Fantus, I.G., Nagy, A., Gerber, H.P., Ferrara, N., Pawson, T., Quaggin, S.E.: Soluble FLT1 binds lipid microdomains in podocytes to control cell morphology and glomerular barrier function. Cell. 151(2), 384-399 (2012). https://doi.org/10.1016/j.cell. 2012.08.037

27. Galeano, B., Klootwijk, R., Manoli, I., Sun, M., Ciccone, C., Darvish, D., Starost, M.F., Zerfas, P.M., Hoffmann, V.J., Hoogstraten-Miller, S., Krasnewich, D.M., Gahl, W.A., Huizing, M.: Mutation in the key enzyme of sialic acid biosynthesis causes severe glomerular proteinuria and is rescued by $\mathrm{N}$ acetylmannosamine. J. Clin. Invest. 117(6), 1585-1594 (2007). https://doi.org/10.1172/JCI30954

28. Merscher, S., Fornoni, A.: Podocyte pathology and nephropathy sphingolipids in glomerular diseases. Front Endocrinol (Lausanne). 5, 127 (2014). https://doi.org/10.3389/fendo.2014.00127

29. Charest, P.M., Roth, J.: Localization of sialic acid in kidney glomeruli: regionalization in the podocyte plasma membrane and loss in experimental nephrosis. Proc. Natl. Acad. Sci. U. S. A. 82(24), 8508-8512 (1985). https://doi.org/10.1073/pnas.82.24.8508

30. Mikulak, J., Singhal, P.C.: HIV-1 entry into human podocytes is mediated through lipid rafts. Kidney Int. 77(1), 72-73; author reply 73-74 (2010). https://doi.org/10.1038/ki.2009.366

31. Varchetta, S., Lusso, P., Hudspeth, K., Mikulak, J., Mele, D., Paolucci, S., Cimbro, R., Malnati, M., Riva, A., Maserati, R., Mondelli, M.U., Mavilio, D.: Sialic acid-binding Ig-like lectin-7 interacts with HIV-1 gp120 and facilitates infection of CD4pos T cells and macrophages. Retrovirology. 10, 154 (2013). https://doi. org/10.1186/1742-4690-10-154

32. Abou Daher, A., El Jalkh, T., Eid, A.A., Fornoni, A., Marples, B., Zeidan, Y.H.: Translational Aspects of Sphingolipid Metabolism in Renal Disorders. Int J Mol Sci. 18(12), (2017). https://doi.org/10. 3390/ijms 18122528

33. Bruggeman, L.A., Dikman, S., Meng, C., Quaggin, S.E., Coffman, T.M., Klotman, P.E.: Nephropathy in human immunodeficiency virus-1 transgenic mice is due to renal transgene expression. J. Clin. Invest. 100(1), 84-92 (1997). https://doi.org/10.1172/ JCI1 19525

34. Saleem, M.A., O'Hare, M.J., Reiser, J., Coward, R.J., Inward, C.D., Farren, T., Xing, C.Y., Ni, L., Mathieson, P.W., Mundel, P.: A conditionally immortalized human podocyte cell line demonstrating nephrin and podocin expression. J. Am. Soc. Nephrol. 13(3), 630638 (2002)

35. Kopp, J.B., Klotman, M.E., Adler, S.H., Bruggeman, L.A., Dickie, P., Marinos, N.J., Eckhaus, M., Bryant, J.L., Notkins, A.L., Klotman, P.E.: Progressive glomerulosclerosis and enhanced renal accumulation of basement membrane components in mice transgenic for human immunodeficiency virus type 1 genes. Proc. Natl. Acad. Sci. U. S. A. 89(5), 1577-1581 (1992). https://doi. org/10.1073/pnas.89.5.1577

36. Hirabayashi, Y., Hyogo, A., Nakao, T., Tsuchiya, K., Suzuki, Y., Matsumoto, M., Kon, K., Ando, S.: Isolation and characterization of extremely minor gangliosides, GM1b and GD1 alpha, in adult bovine brains as developmentally regulated antigens. J. Biol. Chem. 265(14), 8144-8151 (1990)

37. Kannagi, R., Cochran, N.A., Ishigami, F., Hakomori, S., Andrews, P.W., Knowles, B.B., Solter, D.: Stage-specific embryonic antigens (SSEA-3 and -4) are epitopes of a unique globo-series ganglioside isolated from human teratocarcinoma cells. EMBO J. 2(12), 23552361 (1983)

38. Saito, S., Levery, S.B., Salyan, M.E., Goldberg, R.I., Hakomori, S.: Common tetrasaccharide epitope NeuAc alpha $2-3$ Gal beta $1-$ $>3$ (Neu-ac alpha 2->6)GalNAc, presented by different carrier glycosylceramides or O-linked peptides, is recognized by different antibodies and ligands having distinct specificities. J. Biol. Chem. 269(8), 5644-5652 (1994)

39. Saito, S., Aoki, H., Ito, A., Ueno, S., Wada, T., Mitsuzuka, K., Satoh, M., Arai, Y., Miyagi, T.: Human alpha2,3-sialyltransferase (ST3Gal II) is a stage-specific embryonic antigen-4 synthase. J. Biol. Chem. 278(29), 26474-26479 (2003). https://doi.org/10. 1074/jbc.M213223200

40. Reivinen, J., Holthofer, H., Miettinen, A.: A cell-type specific ganglioside of glomerular podocytes in rat kidney: an O-acetylated GD3. Kidney Int. 42(3), 624-631 (1992). https://doi.org/10.1038/ ki.1992.327 
41. Holthofer, H., Reivinen, J., Miettinen, A.: Nephron segment and cell-type specific expression of gangliosides in the developing and adult kidney. Kidney Int. 45(1), 123-130 (1994). https://doi.org/10. 1038/ki.1994.14

42. Kasembeli, A.N., Duarte, R., Ramsay, M., Mosiane, P., Dickens, C., Dix-Peek, T., Limou, S., Sezgin, E., Nelson, G.W., Fogo, A.B., Goetsch, S., Kopp, J.B., Winkler, C.A., Naicker, S.: APOL1 risk variants are strongly associated with HIV-associated nephropathy in black south Africans. J. Am. Soc. Nephrol. 26(11), 2882-2890 (2015). https://doi.org/10.1681/ASN.2014050469

43. Madhavan, S.M., O'Toole, J.F., Konieczkowski, M., Ganesan, S., Bruggeman, L.A., Sedor, J.R.: APOL1 localization in normal kidney and nondiabetic kidney disease. J. Am. Soc. Nephrol. 22(11), 2119-2128 (2011). https://doi.org/10.1681/ASN.2011010069

44. Sezgin, E., Levental, I., Mayor, S., Eggeling, C.: The mystery of membrane organization: composition, regulation and roles of lipid rafts. Nat Rev Mol Cell Biol. 18(6), 361-374 (2017). https:/doi. org/10.1038/nrm.2017.16

45. Najafian, B., Svarstad, E., Bostad, L., Gubler, M.C., Tondel, C., Whitley, C., Mauer, M.: Progressive podocyte injury and globotriaosylceramide (GL-3) accumulation in young patients with Fabry disease. Kidney Int. 79(6), 663-670 (2011). https://doi.org/ 10.1038/ki.2010.484

46. Tatematsu, M., Imaida, K., Ito, N., Togari, H., Suzuki, Y., Ogiu, T.: Sandhoff disease. Acta Pathol. Jpn. 31(3), 503-512 (1981). https:// doi.org/10.1111/j.1440-1827.1981.tb01391.x

47. Nichols, B., Jog, P., Lee, J.H., Blackler, D., Wilmot, M., D'Agati, V., Markowitz, G., Kopp, J.B., Alper, S.L., Pollak, M.R., Friedman, D.J.: Innate immunity pathways regulate the nephropathy gene Apolipoprotein L1. Kidney Int. 87(2), 332-342 (2015). https://doi.org/10.1038/ki.2014.270

48. Chigorno, V., Palestini, P., Sciannamblo, M., Dolo, V., Pavan, A., Tettamanti, G., Sonnino, S.: Evidence that ganglioside enriched domains are distinct from caveolae in MDCK II and human fibroblast cells in culture. Eur. J. Biochem. 267(13), 4187-4197 (2000). https://doi.org/10.1046/j.1432-1327.2000.01454.x

49. Malekkou, A., Samarani, M., Drousiotou, A., Votsi, C., Sonnino, S., Pantzaris, M., Chiricozzi, E., Zamba-Papanicolaou, E., Aureli, M., Loberto, N., Christodoulou, K.: Biochemical Characterization of the GBA2 c.1780G $>$ C Missense Mutation in Lymphoblastoid Cells from Patients with Spastic Ataxia. Int J Mol Sci. 19(10), (2018). https://doi.org/10.3390/ijms 19103099

50. Prinetti, A., Chigorno, V., Tettamanti, G., Sonnino, S.: Sphingolipid-enriched membrane domains from rat cerebellar granule cells differentiated in culture. A compositional study. J Biol Chem. 275(16), 11658-11665 (2000). https://doi.org/10. $1074 / \mathrm{jbc} .275 .16 .11658$

51. Mikulak, J., Di Vito, C., Zaghi, E., Mavilio, D.: Host immune responses in HIV-1 infection: the emerging pathogenic role of
Siglecs and their clinical correlates. Front. Immunol. 8, 314 (2017). https://doi.org/10.3389/fimmu.2017.00314

52. Valsecchi, M., Aureli, M., Mauri, L., Illuzzi, G., Chigorno, V., Prinetti, A., Sonnino, S.: Sphingolipidomics of A2780 human ovarian carcinoma cells treated with synthetic retinoids. J. Lipid Res. 51(7), 1832-1840 (2010). https://doi.org/10.1194/jlr.M004010

53. Samarani, M., Loberto, N., Solda, G., Straniero, L., Asselta, R., Duga, S., Lunghi, G., Zucca, F.A., Mauri, L., Ciampa, M.G., Schiumarini, D., Bassi, R., Giussani, P., Chiricozzi, E., Prinetti, A., Aureli, M., Sonnino, S.: A lysosome-plasma membranesphingolipid axis linking lysosomal storage to cell growth arrest. FASEB J. 32(10), 5685-5702 (2018). https://doi.org/10.1096/fj. 201701512RR

54. Di Biase, E., Lunghi, G., Fazzari, M., Maggioni, M., Pome, D.Y., Valsecchi, M., Samarani, M., Fato, P., Ciampa, M.G., Prioni, S., Mauri, L., Sonnino, S., Chiricozzi, E.: Gangliosides in the differentiation process of primary neurons: the specific role of GM1-oligosaccharide. Glycoconj. J. 37, 329-343 (2020). https://doi.org/10. 1007/s10719-020-09919-x

55. Aureli, M., Loberto, N., Lanteri, P., Chigorno, V., Prinetti, A., Sonnino, S.: Cell surface sphingolipid glycohydrolases in neuronal differentiation and aging in culture. J. Neurochem. 116(5), 891-899 (2011). https://doi.org/10.1111/j.1471-4159.2010.07019.x

56. Overkleeft, H.S., Renkema, G.H., Neele, J., Vianello, P., Hung, I.O., Strijland, A., van der Burg, A.M., Koomen, G.J., Pandit, U.K., Aerts, J.M.: Generation of specific deoxynojirimycin-type inhibitors of the non-lysosomal glucosylceramidase. J. Biol. Chem. 273(41), 26522-26527 (1998). https://doi.org/10.1074/jbc. 273.41.26522

57. Dobin, A., Davis, C.A., Schlesinger, F., Drenkow, J., Zaleski, C., Jha, S., Batut, P., Chaisson, M., Gingeras, T.R.: STAR: ultrafast universal RNA-seq aligner. Bioinformatics. 29(1), 15-21 (2013). https://doi.org/10.1093/bioinformatics/bts635

58. Li, H., Handsaker, B., Wysoker, A., Fennell, T., Ruan, J., Homer, N., Marth, G., Abecasis, G., Durbin, R.: Genome project data processing, S.: the sequence alignment/map format and SAMtools. Bioinformatics. 25(16), 2078-2079 (2009). https://doi.org/10. 1093/bioinformatics/btp352

59. Anders, S., Pyl, P.T., Huber, W.: HTSeq-a Python framework to work with high-throughput sequencing data. Bioinformatics. 31(2), 166-169 (2015). https://doi.org/10.1093/bioinformatics/btu638

60. Love, M.I., Huber, W., Anders, S.: Moderated estimation of fold change and dispersion for RNA-seq data with DESeq2. Genome Biol. 15(12), 550 (2014). https://doi.org/10.1186/s13059-0140550-8

Publisher's note Springer Nature remains neutral with regard to jurisdictional claims in published maps and institutional affiliations. 